\title{
Computational study of polycyclic aromatic hydrocarbons growth by vinylacetylene addition
}

Peng Liu ${ }^{a^{*}}$, Yiran Zhang ${ }^{\mathrm{b}}$, Zepeng Li ${ }^{\mathrm{a}}$, Anthony Bennett ${ }^{\mathrm{a}}$, He Lin ${ }^{\mathrm{b} *}$, S. Mani Sarathy ${ }^{\mathrm{a}}$, William L. Roberts ${ }^{\mathrm{a}}$

${ }^{a}$ King Abdullah University of Science and Technology (KAUST), Clean Combustion Research Center, Thuwal 239556900, Saudi Arabia

${ }^{b}$ Key Laboratory for Power Machinery and Engineering of Ministry of Education, School of Mechanical Engineering, Shanghai Jiao Tong University, Shanghai 200240, China

Abstract: The growth of polycyclic aromatic hydrocarbons (PAH) can proceed via multiple chemical mechanisms. The mechanism of naphthyl radical and vinylacetylene $\left(\mathrm{C}_{4} \mathrm{H}_{4}\right)$ addition reaction has been systematically investigated in this computational study. A combination of DFT/B3LYP/6-311+G(d,p), CCSD/6$311+\mathrm{G}(\mathrm{d}, \mathrm{p})$ and CBS-QB3 methods were performed to calculate the potential energy surfaces. It revealed that the products, including phenanthrene, anthracene, a PAH with a five-membered ring structure, and PAH with a $\mathrm{C}_{4} \mathrm{H}_{3}$ radical substitution, can be formed in $\mathrm{A}_{2}-1$ (1-naphthyl) $+\mathrm{C}_{4} \mathrm{H}_{4}$ and $\mathrm{A}_{2}-2$ (2-naphthyl) $+\mathrm{C}_{4} \mathrm{H}_{4}$ reaction networks. The reaction rate constants at 0.1-100 atm were evaluated by RRKM theory by solving the master equation in the temperature range of 800-2500 K, which showed that the rate constants of reactions $A_{2}-1\left(A_{2-}\right.$ 2) $+\mathrm{C}_{4} \mathrm{H}_{4} \rightarrow$ product $+\mathrm{H}$ are highly temperature-dependent but nearly pressure-independent. The distribution of products was investigated in a $0-\mathrm{D}$ batch reactor, wherein the initial reactant concentrations were taken from experimental measurements. The results showed that adduct intermediates were the main products at low temperature $(\mathrm{T}<1000 \mathrm{~K})$, and the phenanthrene and $\mathrm{PAH}$ with $\mathrm{C}_{4} \mathrm{H}_{3}$ radical substitution became the dominant products at temperatures where PAHs and soot form in flames ( $\mathrm{T}>1000 \mathrm{~K}$ ). It was observed that a significant amount of phenanthrene is formed from $\mathrm{PAH}$ with a $\mathrm{C}_{4} \mathrm{H}_{3}$ radical substitution with the assistance of $\mathrm{H}$ atom. Reaction pathway sensitivity analysis for the $\mathrm{PAH}$ radical $+\mathrm{C}_{4} \mathrm{H}_{4}$ reaction system was performed and showed that the new benzene rings are more likely to be generated near the zig-zag edge surface site instead of the free edge. For the development of a PAH mechanism, the analogous treatment of rate constants for larger PAH radical + $\mathrm{C}_{4} \mathrm{H}_{4}$ reaction system are discussed. The formation rate of naphthalene from the reaction of phenyl+ $\mathrm{C}_{4} \mathrm{H}_{4} \mathrm{was}$ found to be very close to that of phenanthrene from the reaction of naphthyl+ $\mathrm{C}_{4} \mathrm{H}_{4}$, suggesting that the analogous treatment of the rates is reasonable in PAH mechanisms.

Keywords: PAHs, soot, nucleation, mechanism, kinetics. 


\section{Introduction}

The chemistry of polycyclic aromatic hydrocarbons (PAHs) draws significant attention in combustion, atmospheric, and material carbon science. One reason for this interest is because PAH chemistry has improved the production efficiency of 2-D and 3-D carbon materials, which present outstanding thermal conductivity as well as mechanical and electrical properties, via a chemical vapor deposition (CVD) method [1-3]. However, controlling the quality of the formed 2-D and 3-D materials in commercial application remains a challenge, due to a lack of fundamental knowledge about the formation mechanism of PAHs $[4,5]$. Furthermore, the formation mechanism of PAHs is a major concern in the combustion community, since PAHs formed during incomplete combustion of hydrocarbon are regarded as soot precursors [6-8]. Developing accurate models of PAH and soot formation is important for many reasons, including the development of cleaner combustion engines $[9,10]$ and understanding the formation of interstellar dust [11, 12].

The growth of PAHs, starting with benzene $\left(\mathrm{A}_{1}\right)$ in flames, has long been modeled by the hydrogenabstraction/acetylene-addition (HACA) framework originally proposed by Frenklach and coworkers [13]. Following a more extensive approach, Mebel et al. [14] discussed the branching ratio of products in a benzene + acetylene reaction system. The results confirmed that naphthalene $\left(\mathrm{A}_{2}\right)$ was the dominant product of the HACA framework over a wide range of temperatures and pressures. On the other hand, recent experimental and theoretical results indicate that the HACA pathway does not explain the addition of new benzene rings (such as naphthalene to phenanthrene) on PAHs. Parker et al. [15] investigated the reaction of 1- and 2-naphthyl radical and acetylene at combustion-like temperatures using photoionization mass spectrometry. The results revealed that the dominant product was acenaphthylene produced via a HACA-based reaction scheme, while anthracene and phenanthrene were not detected. Liu et al. [16] further investigated the possible reasons for these observations, and suggested that the site effect should account for this phenomenon. They found that the $\mathrm{H}$ abstraction and $\mathrm{C}_{2} \mathrm{H}_{2}$ addition reactions on the ortho-position (relative to the existing $\mathrm{C}_{2} \mathrm{H}$ substitution) and bay surface site, were kinetically unfavored, when compared to other site options, due to the relatively high energy barrier and orientation hindrance effect. In this way, the incremental addition of new benzene rings is unlikely to occur when the reactant PAH is as large as, or larger than, naphthalene, and PAHs with five-membered rings are the preferred products in the HACA framework. The non-radical based $\mathrm{PAH}-\mathrm{C}_{2} \mathrm{H}_{2}$ pathway, in which $\mathrm{C}_{2} \mathrm{H}_{2}$ attacks the closeshell PAH molecule followed by an $\mathrm{H}_{2}$ release, can introduce a new benzene ring on armchair and bridge surface sites of PAHs [7]. This pathway describes possible PAHs growth in regions where radical concentration is very low, such as in the post-flame region and interstellar space. However, the majority of PAHs are formed in sooting flame, where radical species are abundant [8, 17]. Raj et al. [18] investigated the role of PAH growth initiated by propargyl $\left(\mathrm{C}_{3} \mathrm{H}_{3}\right)$ addition onto naphthalene and the naphthyl radical, and concluded that the new benzene ring may form if $\mathrm{C}_{3} \mathrm{H}_{3}$ attacks the zig-zag site of $\mathrm{PAH}$. However, the low concentration of $\mathrm{C}_{3} \mathrm{H}_{3}$ may limit its 
application in some flames. Therefore, other radical-based pathways responsible for the addition of new benzene rings on PAH molecules should be explored.

One likely mechanism to produce new benzene rings is the addition reaction of vinylacetylene $\left(\mathrm{C}_{4} \mathrm{H}_{4}\right)$ and $\mathrm{PAH}$ radicals, since a second addition of other carbon species is not required during the cyclization process. $\mathrm{C}_{4} \mathrm{H}_{4}$ is abundant in combustion environments, including premixed ethylene, benzene, toluene, and gasoline flames [1922]. The measured mole fraction of $\mathrm{C}_{4} \mathrm{H}_{4}$ is up to $2 \times 10^{-3}$, comparable to $\mathrm{C}_{2} \mathrm{H}_{2}$ [19-22]. Correlations between $\mathrm{C}_{4} \mathrm{H}_{4}$ and PAH formation are greater under CVD process conditions. A significant amount of PAHs, including naphthalene, phenanthrene, and pyrene, were detected by Norinaga et al. in a CVD process with acetylene as the carbon source [23]. They analyzed the concentration of gas-phase compounds further, and their results showed that the major active species was $\mathrm{C}_{4} \mathrm{H}_{4}$ with a mole fraction of $3 \times 10^{-1}$.

Among the addition reactions of $\mathrm{C}_{4} \mathrm{H}_{4}$ with aromatic species, the phenyl+ $\mathrm{C}_{4} \mathrm{H}_{4}$ reaction has received special attention [24-29]. The phenyl+ $\mathrm{C}_{4} \mathrm{H}_{4}$ reaction was first considered in the PAHs mechanism by Appel et al. [27], and modelling results showed that phenyl+ $\mathrm{C}_{4} \mathrm{H}_{4}$ reaction is the main route of naphthalene formation in ethylene flames. Subsequently, the addition reactions of $\mathrm{C}_{4} \mathrm{H}_{4}$ with $\mathrm{PAHs}$ radical have been merged into PAH mechanisms, assuming reaction rate coefficients to be equal to that of phenyl $+\mathrm{C}_{4} \mathrm{H}_{4} \rightarrow$ naphthalene+H $[28,30-33]$. The rate coefficients of the reaction phenyl $+\mathrm{C}_{4} \mathrm{H}_{4} \rightarrow$ naphthalene+H come primarily from two sources. One was suggested by Appel et al. [27] with the expression of $2.5 \times 10^{29} \times \mathrm{T}^{-4.43} \times \exp (-26400 / \mathrm{RT}) \mathrm{cm}^{3} \mathrm{~mol}^{-1} \mathrm{~s}^{-1}$. Application examples include the PAHs mechanisms proposed by Pang et al. [32] and Chernov et al. [28]. However, the rate coefficient may be problematic, as the pre-exponential factor at $1000 \mathrm{~K}$ is $1.6 \times 10^{16} \mathrm{~cm}^{3} \mathrm{~mol}^{-1} \mathrm{~s}^{-1}$, which is beyond the physical collision limit $\left(-10^{14} \mathrm{~cm}^{3} \mathrm{~mol}^{-1} \mathrm{~s}^{-1}\right)$. The other one was suggested by Aguilera-Iparraguirre et al. [34] using density functional theory (DFT) and transition state theory (TST) calculation. The rates is used in the PAH mechanism proposed by Wang et al. [33]. Here, the reaction rate coefficients of $\mathrm{C}_{4} \mathrm{H}_{4}+$ phenyl $\rightarrow$ naphthalene $+\mathrm{H}$ were assumed to be equal to that of the entrance elementary reaction step $\left(\mathrm{C}_{4} \mathrm{H}_{4}\right.$ molecule attaches to the phenyl radical). Such treatment may exaggerate the role of $\mathrm{C}_{4} \mathrm{H}_{4}$ in $\mathrm{PAHs}$ growth, as the formation of other isomers and the $\mathrm{H}$ loss from the $\mathrm{C}_{6} \mathrm{H}_{5} \mathrm{C}_{4} \mathrm{H}_{4}$ intermediate are probable. This is evidenced by the experimental study of Zhao et al.[26], in which trans-1-phenylvinylacetylene and the 4-phenylvinylacetylene were also the main products in the reaction of phenyl $+\mathrm{C}_{4} \mathrm{H}_{4}$. The formation of trans-1-phenylvinylacetylene and 4-phenylvinylacetylene is interesting, as they are suitable precursors for the chemical coalescence inception pathway due to their high reactivity and concentration in flame.

Chemical coalescence inception pathways are the other driving force for determining whether appreciable amounts of PAHs with radical substitutions can be produced from $\mathrm{PAH}$ radical $+\mathrm{C}_{4} \mathrm{H}_{4}$ reaction in sooting flames. Furthermore, it is notable that phenyl radical only consists of free edges, but larger PAH radicals contain free 
edge and zig-zag surface sites at least. Therefore, the accuracy of the analogy treatment of reaction rates from phenyl $+\mathrm{C}_{4} \mathrm{H}_{4}$ reaction to $\mathrm{PAH}$ radical $+\mathrm{C}_{4} \mathrm{H}_{4}$ reactions requires further investigation, as the kinetics are highly sensitive to the type of targeted surface site instead of the size of PAHs in growth and oxidation processes [3539]. Thus, obtaining reliable reaction rate coefficients and yield distribution of products in $\mathrm{PAH}$ radical $+\mathrm{C}_{4} \mathrm{H}_{4}$ reaction system is crucial to better understand PAH formation in flames and materials production.

The addition reaction of $\mathrm{C}_{4} \mathrm{H}_{4}$ with $\mathrm{PAH}$ radicals has received little attention. To the best of our knowledge, only the addition reactions between $\mathrm{C}_{4} \mathrm{H}_{4}$ and 1-naphthyl/2-naphthyl were recently assessed by Zhao et al. [40], with an emphasis on the PAH formation at low temperatures (70-180 K) relevant to conditions on Titan. Naphthalene $\left(A_{2}\right)$ is the simplest PAH with free-edge and zig-zag surface sites, providing an opportunity to explore the site effect of $\mathrm{PAH}$ radical $+\mathrm{C}_{4} \mathrm{H}_{4}$ reactions using high-level theoretical procedures. In this study, the addition reactions of $\mathrm{C}_{4} \mathrm{H}_{4}+1$-naphthyl radical $\left(\mathrm{A}_{2}-1\right)$ and $\mathrm{C}_{4} \mathrm{H}_{4}+2$-naphthyl radical $\left(\mathrm{A}_{2}-2\right)$, are systematically investigated with an emphasis on PAH formation at flame temperatures. The potential energy surfaces (PES) are explored by a combination of density functional theory (DFT) B3LYP/6-311+G(d,p), CCSD(T)/6-311+G(d,p), and CBS-QB3 methods. Reaction rate coefficients were subsequently determined by RRKM theory by solving the master equation at various temperatures and pressures. Based on the kinetic parameters, the potential yield distributions of products are investigated at combustion conditions via a 0-D batch reactor. Finally, reaction pathway sensitivity analysis and the analogous treatment for kinetic parameters in other $\mathrm{PAH}$ radical $+\mathrm{C}_{4} \mathrm{H}_{4}$ reaction systems for PAH mechanism development are discussed.

\section{Calculation details}

In this study, the close-shell and open-shell structures were optimized at the DFT B3LYP 6-311 G+(d,p) level, with restricted wave function and unrestricted wave functions respectively [41-43]. The same method was utilized to obtain frequency information with a correction factor of 0.967 , which was originally obtained for the DFT B3LYP 6-311 G+(3df,2p) method [44]. To improve energy accuracy, the sum of electronic and zero-point energy was refined with the CBS-QB3 method, a single-determinant reference state method. The root-mean-square deviation of CBS-QB3 energy for hydrocarbon molecule was $1.49 \mathrm{kcal} / \mathrm{mol}$ [45]. T1 diagnostics were performed at the $\operatorname{CCSD}(\mathrm{T}) / 6-311+\mathrm{G}(\mathrm{d}, \mathrm{p})$ level with DFT structures to assess whether the CBS-QB3 method was suitable for the energy calculation. A larger T1 value means that a multiple-determinant reference state method should be applied to calculate the energy. Here, the threshold value of T1 was considered as 0.02 for close-shell structures, and 0.045 for open-shell structures [21, 46, 47]. T1 diagnostics results indicated that the energies of 27 molecules among the 150 molecules in this study should be described by a multiple-determinant reference state method. Energy calculations using the multiple-determinant reference state CASPT2 method can be used for these structures. The strength of the CASPT2 method is its ability to give exact spin states, but its application for large 
molecule is limited by the computational cost. The number of active orbitals used in CASPT2 calculation should be larger than the minimum required to describe the strong (static) correlation, otherwise its accuracy may be lower than the CBS-QB3 method [48]. Our case showed that 500 GB memory was not sufficient for the CASPT2 $(6,6)$ calculation, not to mention the more active orbitals calculation. In this study, all energies were given at the CBS-QB3 level and used in rate calculation, although the energies of species with high T1 diagnostic values may not be entirely reliable. Fortunately, the energies of these species were of lesser importance in this study, as the pathways where these structures existed were significantly less competitive than other pathways in the kinetic analysis. All T1 diagnostics values are listed in Table S1 in the supplementary material. In addition, two transition states of the entrance reactions $\left(\mathrm{C}_{4} \mathrm{H}_{4}\right.$ attaches to naphthyl radical) failed to converge in the $\mathrm{CCSD}(\mathrm{t}) / 6-31+\mathrm{G}(\mathrm{d})$ step in CBS-QB3 calculations due to spin contamination. To make our comparisons more rigorous, the energy barriers for all competing entrance reactions were taken from the DFT/B3LYP/6-311+G(d,p) level in rate calculations. All quantum chemistry calculations were performed using a Gaussian 09 software package with version D.01.

Based on the obtained quantum chemistry results, including vibrational frequencies, energy barriers, moments of inertia, and other molecular parameters, we evaluated the global reaction rate coefficients (e.g., $\mathrm{A}_{2}-1+\mathrm{C}_{4} \mathrm{H}_{4} \rightarrow$ Product $\mathrm{A}+\mathrm{H}$ ) via RRKM theory by solving the master equation. The MultiWell suite of codes (MultiWell2017.1) was utilized for the kinetic calculations. PES results showed that the investigated $\mathrm{A}_{2}-1$ (or $\left.\mathrm{A}_{2}-2\right)+\mathrm{C}_{4} \mathrm{H}_{4}$ reactions were multi-well bimolecular reactions, as illustrated by (1). Three steps were taken to evaluate the global reaction rate coefficients. Specifically, the rate coefficient of Intermediate $1 \rightarrow \mathrm{A}_{2}-1$ (or $\mathrm{A}_{2}-2$ ) $+\mathrm{C}_{4} \mathrm{H}_{4} \mathrm{reaction}$ was determined by initiating the Intermediate1 with thermal energy distribution. Subsequently, the rate coefficients of recombination reaction $\mathrm{A}_{2}-1$ (or $\left.\mathrm{A}_{2}-2\right)+\mathrm{C}_{4} \mathrm{H}_{4} \rightarrow$ Intermediatel were calculated via the combination of its reverse reaction rate coefficients and equilibrium constants. Finally, the global reaction rate coefficients of $\mathrm{A}_{2}-1$ (or $\left.\mathrm{A}_{2}-2\right)+\mathrm{C}_{4} \mathrm{H}_{4} \rightarrow$ Product $\mathrm{A}+\mathrm{H}$ were evaluated by multiplying the yield of Product $\mathrm{A}$ and the rate coefficients of $\mathrm{A}_{2}-1$ (or $\left.\mathrm{A}_{2}-2\right)+\mathrm{C}_{4} \mathrm{H}_{4} \rightarrow$ Intermediate1. The yield of Product $\mathrm{A}$ was obtained by initiating the Intermediate1 with chemical activation energy distribution. The simulation time was long enough for the reaction to reach the equilibrium. In this way, the yield of Product A was a constant under the given temperature and pressure conditions.

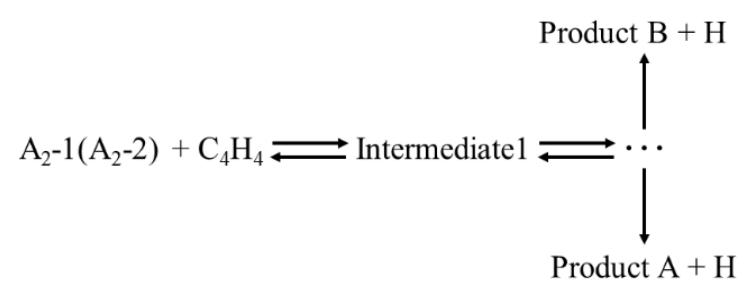


The reaction rate coefficients were evaluated in the temperature range of $800-2500 \mathrm{~K}$ and pressure ranges of 0.1-100 atm. In MultiWell calculations, the maximum energy was set as $300,000 \mathrm{~cm}^{-1}$. The translational and vibrational temperatures were set to be equal. The sums and densities of states were calculated by exact count with an energy grain size of $10 \mathrm{~cm}^{-1}$. Both the temperature-independent exponential-down model with $\left\langle\Delta \mathrm{E}_{\mathrm{down}}\right\rangle$ $=260 \mathrm{~cm}^{-1}$ [49], and the temperature-dependent exponential down model $\left\langle\Delta \mathrm{E}_{\text {down }}\right\rangle=200 \times(\mathrm{T} / 300 \mathrm{~K})^{0.85} \mathrm{~cm}^{-1}[50]$ were used to describe the collisional energy transfer. In $\mathrm{A}_{2}-1+\mathrm{C}_{4} \mathrm{H}_{4}(\mathrm{C} 1)$ reaction systems, the calculated yields of various products with these two collisional energy transfer models were almost the same, as presented in Fig. S1 in the supplementary material. In this study, the temperature-independent exponential-down model with $\left\langle\Delta \mathrm{E}_{\mathrm{down}}\right\rangle=260 \mathrm{~cm}^{-1}$ was employed for other reaction cases. Argon was selected as the bath gas collider. The Lennard-Jones parameters $\sigma$ and $\varepsilon / \mathrm{k}_{\mathrm{B}}$ of Argon were equal to $3.47 \AA$ and $114 \mathrm{~K}$, respectively. In addition, the Lennard-Jones parameters of the PAH structures were assumed to be equal with that of phenanthrene $\left(\mathrm{A}_{3}\right)$, as the values are mainly determined by molecule size [51]. The symmetry numbers of all local structures were determined according to the study by Ducan [52]. The real frequencies below $100 \mathrm{~cm}^{-1}$ were carefully examined, and all internal rotations were treated as 1-D hindered rotations [35]. The torsional potential energy and the rotation constant as a function of dihedral angle were obtained via the relaxed potential energy surface scans at the DFT/B3LYP/6-311 G+(d,p) level, and are shown in Table S7 in the supplementary material. A dihedral angle step of $20^{\circ}$ was used in the scan calculation. The number of stochastic trials changed from $1 \times 10^{6}$ to $1 \times 10^{7}$ to keep statistical fluctuations below $3 \%$.

A 0-D batch reactor in Chemkin-Pro software was used to investigate the yield distribution and the formation rate of new benzene in $\mathrm{A}_{2}-\mathrm{H}-\mathrm{C}_{4} \mathrm{H}_{4}-\mathrm{H}_{2}-\mathrm{N}_{2}\left(\mathrm{~A}_{1}-\mathrm{H}-\mathrm{C}_{4} \mathrm{H}_{4}-\mathrm{H}_{2}-\mathrm{N}_{2}\right)$ reaction system, with $\mathrm{A}_{2}\left(\mathrm{~A}_{1}\right), \mathrm{H}, \mathrm{C}_{4} \mathrm{H}_{4}, \mathrm{H}_{2}$ and $\mathrm{N}_{2}$ as the initial reactants. The mole fractions of $\mathrm{A}_{2}\left(\mathrm{~A}_{1}\right)$ and $\mathrm{C}_{4} \mathrm{H}_{4}$ were set as $6.18 \times 10^{-5}$ and $4.0 \times 10^{-4}$ respectively, as measured in a premixed sooting ethylene flame by Castaldi et al. [17]. The mole fractions of $\mathrm{H}, \mathrm{H}_{2}$ and $\mathrm{N}_{2}$ were assumed to equal $1.0 \times 10^{-4}, 1 \times 10^{-2}$, and $0.9894382\left(\mathrm{~N}_{2}=1-\mathrm{A}_{2}-\mathrm{C}_{4} \mathrm{H}_{4}-\mathrm{H}-\mathrm{H}_{2}\right)$, respectively. The reaction network and corresponding kinetics considered in $\mathrm{A}_{1}-\mathrm{H}-\mathrm{C}_{4} \mathrm{H}_{4}-\mathrm{H}_{2}-\mathrm{N}_{2}$ reaction system are listed in Table 1. The kinetic information for $\mathrm{A}_{2}-\mathrm{H}-\mathrm{C}_{4} \mathrm{H}_{4}-\mathrm{H}_{2}-\mathrm{N}_{2}$ reaction system comes from this study, as shown in Table 2. It should be noted that $A_{2}-1$ and $A_{2}-2$ are generated via the $H$ abstraction reactions $\left(A_{2}+H \rightarrow A_{2}-1+H_{2}\right.$ and $A_{2}+H \rightarrow A_{2}-$ $2+\mathrm{H}_{2}$ ) in the $\mathrm{A}_{2}-\mathrm{H}-\mathrm{C}_{4} \mathrm{H}_{4}-\mathrm{H}_{2}-\mathrm{N}_{2}$ reaction system. The $\mathrm{H}$ abstraction reaction rate constants came from [16]. The residence time in 0-D batch reactor is set as $10 \mathrm{~ms}$, and investigated temperature ranges from 1000-1750 K.

\section{Results and discussion}

$\mathrm{A}_{2}-1$ and $\mathrm{A}_{2}-2$ exist simultaneously in the flame, and their concentrations are determined by the $\mathrm{H}$ abstraction reactions of $\mathrm{A}_{2}$ with $\mathrm{H}, \mathrm{OH}, \mathrm{CH}_{3}$ and other active radicals. In this study, both $\mathrm{A}_{2}-1+\mathrm{C}_{4} \mathrm{H}_{4}$ and $\mathrm{A}_{2}-2+\mathrm{C}_{4} \mathrm{H}_{4}$ reactions 
were studied. Each $\mathrm{C}$ atom on the $\mathrm{C}_{4} \mathrm{H}_{4}$ molecule is active, due to the double and triple bonds, and can attack active $\mathrm{C}$ atoms on PAH molecules. In this way, there are eight entrance channels, if the possibilities of all reaction are considered. To simplify the complicated $\mathrm{A}_{2}-1+\mathrm{C}_{4} \mathrm{H}_{4}$ and $\mathrm{A}_{2}-2+\mathrm{C}_{4} \mathrm{H}_{4}$ reaction systems in a reasonable manner, we first investigated the rates of every entrance reaction. As shown in Fig.1 (a), the rate coefficients of $\mathrm{A}_{2}-1+\mathrm{C}_{4} \mathrm{H}_{4}$ entrance reactions with $\mathrm{C}(2)$ and $\mathrm{C}(3)$ atoms on $\mathrm{C}_{4} \mathrm{H}_{4}$ molecule as the target sites are lower than that of $\mathrm{C}(1)$ and $\mathrm{C}(4)$ atoms by at least one order of magnitude at $1500 \mathrm{~K}$. The result is mainly due to the difference in the energy barriers. The energy barriers of addition reactions involving C(2) $(8.1 \mathrm{kcal} / \mathrm{mol})$ and C(3) (7.2 kcal $/ \mathrm{mol})$ are more than twice that of reactions involving C(1) $(3.1 \mathrm{kcal} / \mathrm{mol})$ and $\mathrm{C}(4)(2.3 \mathrm{kcal} / \mathrm{mol})$. The kinetic feature of $\mathrm{A}_{2^{-}}$ $2+\mathrm{C}_{4} \mathrm{H}_{4}$ is similar to that of $\mathrm{A}_{2}-1+\mathrm{C}_{4} \mathrm{H}_{4}$, as shown in Fig.1 (b). Kinetic results indicate that PAH radicals attacked by the $\mathrm{C}(1)$ and $\mathrm{C}(4)$ atoms on $\mathrm{C}_{4} \mathrm{H}_{4}$ molecule are more favorable than by the $\mathrm{C}(2)$ and $\mathrm{C}(3)$ atoms. In this study, we only discuss the reaction possibilities of $\mathrm{A}_{2}-1+\mathrm{C}_{4} \mathrm{H}_{4}$ and $\mathrm{A}_{2}-2+\mathrm{C}_{4} \mathrm{H}_{4}$ reactions with $\mathrm{C}(1)$ and $\mathrm{C}(4)$ atoms on $\mathrm{C}_{4} \mathrm{H}_{4}$ molecules as the target sites, namely $\mathrm{A}_{2}-1+\mathrm{C}_{4} \mathrm{H}_{4}(\mathrm{C} 1), \mathrm{A}_{2}-1+\mathrm{C}_{4} \mathrm{H}_{4}(\mathrm{C} 4), \mathrm{A}_{2}-2+\mathrm{C}_{4} \mathrm{H}_{4}(\mathrm{C} 1)$, and $\mathrm{A}_{2}-2+\mathrm{C}_{4} \mathrm{H}_{4}$ (C1) reaction systems. It should be noted that a complex is first formed between $\mathrm{A}_{2}-1$ and $\mathrm{C}_{4} \mathrm{H}_{4}$ fragments in the study by Zhao et al. [40]. This process was also checked by IRC calculations in this study, as shown in Fig.S2. The complexes with relative strong van-der-Waals force were not found except in $\mathrm{A}_{2}-1+\mathrm{C}_{4} \mathrm{H}_{4}(\mathrm{C} 4)$ system at the DFT/B3LYP/6-311+G(d,p) level. The existence of such complexes mainly influences the kinetic rate in the low temperature region (e.g., $\mathrm{T}<300 \mathrm{~K}$ ), and does not affect the kinetic results at flame temperature due to the short lifetime; therefore, the formation of complexes has been ignored in this study. Two examples of similar treatments can be seen in phenyl $+\mathrm{C}_{4} \mathrm{H}_{4}$ reactions $[29,34]$.

\subsection{Potential energy surface and yield distribution}

\subsection{1 $\mathrm{A}_{2}-1+\mathrm{C}_{4} \mathrm{H}_{4}(\mathrm{C1})$ reaction system}

The PES of the $\mathrm{A}_{2}-1+\mathrm{C}_{4} \mathrm{H}_{4}(\mathrm{C} 1)$ reaction system is shown in Fig. 2. The entrance reaction of $\mathrm{A}_{2}-1$ and $\mathrm{C}_{4} \mathrm{H}_{4}$ (C1) produced the adduct CS2, which split into six channels. Two channels involve the H elimination from the $\mathrm{C}_{4} \mathrm{H}_{4}$ substitution on adduct $\mathrm{CS} 2$ via pathways CS2 $\rightarrow \mathrm{CS} 10 \_\mathrm{P}+\mathrm{H}(46.2 \mathrm{kcal} / \mathrm{mol})$ and CS2 $\rightarrow \mathrm{CS} 11 \_\mathrm{P}+\mathrm{H}(54.8$ $\mathrm{kcal} / \mathrm{mol})$. Here, the energy barrier of $\mathrm{H}$ elimination from the $\mathrm{C}_{4} \mathrm{H}_{4}$ substitution was much higher than from the aromatic rings. Examples include reactions CS6 $\rightarrow$ CS7_P+H $(13.8 \mathrm{kcal} / \mathrm{mol})$ and CS14 $\rightarrow \mathrm{CS} 7 \_\mathrm{P}+\mathrm{H}(28.6$ $\mathrm{kcal} / \mathrm{mol})$. Alternatively, the adduct CS2 may undergo a six-member ring closure to CS3 $(\mathrm{CS} 2 \rightarrow \mathrm{CS} 3,42.4$ $\mathrm{kcal} / \mathrm{mol}$ ). CS3 is a structure with one bare $\mathrm{C}$ atom and two adduct $\mathrm{H}$ atoms, and may lead to the formation of phenanthrene $\left(\mathrm{CS} 7 \_\mathrm{P}\right)$ via two pathways: CS3 $\rightarrow \mathrm{CS} 5 \rightarrow \mathrm{CS} 6 \rightarrow \mathrm{CS} 7 \_\mathrm{P}+\mathrm{H}$ and CS3 $\rightarrow \mathrm{CS} 9 \rightarrow \mathrm{CS} 14 \rightarrow \mathrm{CS} 7 \_\mathrm{P}+\mathrm{H}$. Both pathways involve two $\mathrm{H}$ migration reactions and one $\mathrm{H}$ elimination reaction. In the former pathway, one adduct $\mathrm{H}$ atom first migrates to the adjacent saturated $\mathrm{C}$ atom $(\mathrm{CS} 3 \rightarrow \mathrm{CS} 5,54.6 \mathrm{kcal} / \mathrm{mol})$, then migrates to unsaturated $\mathrm{C}$ atoms $(\mathrm{CS} 5 \rightarrow \mathrm{CS} 6,7.2 \mathrm{kcal} / \mathrm{mol})$. In the latter pathway, the other adduct $\mathrm{H}$ atom first migrates to 
the ortho-position saturated $\mathrm{C}$ atom $(\mathrm{CS} 3 \rightarrow \mathrm{CS} 9,29.0 \mathrm{kcal} / \mathrm{mol})$, then migrates to the unsaturated $\mathrm{C}$ atom $(\mathrm{CS} 9 \rightarrow \mathrm{CS} 14,46.2 \mathrm{kcal} / \mathrm{mol})$. It was noted that the energy barrier of $\mathrm{H}$ transfer reaction $\mathrm{CS} 9 \rightarrow \mathrm{CS} 14(46.2$ $\mathrm{kcal} / \mathrm{mol})$ was higher than that of the similar reaction CS5 $\rightarrow$ CS6 $(7.2 \mathrm{kcal} / \mathrm{mol})$ by 6.4 times, although they share almost the same reaction features. The higher energy barrier in CS9 $\rightarrow$ CS14 reaction may result from the larger coulomb force between the $\mathrm{H}$ atom (donor) and the unsaturated $\mathrm{C}$ atom (acceptor) [21]. In addition, a phenanthrenyl radical (CS15) may form from the 2-H elimination reaction, but this process is kinetically unsupported due to the relatively high energy barrier $(77.7 \mathrm{kcal} / \mathrm{mol})$.

In terms of the energy barrier, the adduct CS2 is more likely to form the CS4 structure, which is featured with $\mathrm{H}$ transfer from the benzene ring to the bare $\beta-\mathrm{C}$ atom on the $\mathrm{C}_{4} \mathrm{H}_{4}$ substitution $(\mathrm{CS} 2 \rightarrow \mathrm{CS} 4,34.3 \mathrm{kcal} / \mathrm{mol})$, as shown in Fig.2. The CS4 structure can lead to the products CS10_P and CS7_P through channels of $\mathrm{CS} 4 \rightarrow \mathrm{CS} 8 \rightarrow \mathrm{CS} 16 \rightarrow \mathrm{CS} 10 \_\mathrm{P}+\mathrm{H}$, and CS4 $\rightarrow \mathrm{CS} 8 \rightarrow \mathrm{CS} 16 \rightarrow \mathrm{CS} 18 \rightarrow \mathrm{CS} 19 \rightarrow \mathrm{CS} 6 \rightarrow \mathrm{CS} 7 \_\mathrm{P}+\mathrm{H}$. The reaction step of $\mathrm{CS} 4 \rightarrow \mathrm{CS} 8$ is a $\mathrm{C}-\mathrm{C}$ rotation process, followed by $\mathrm{H}$ transfer from $\mathrm{C}_{4} \mathrm{H}_{4}$ to the unsaturated $\mathrm{C}$ atom on the benzene ring $(\mathrm{CS} 8 \rightarrow \mathrm{CS} 16,29.0 \mathrm{kcal} / \mathrm{mol})$. It should be noted that the intermediate CS16 can also form directly from CS2 via $\mathrm{H}$ transfer on the $\mathrm{C}_{4} \mathrm{H}_{4}$ substitution. The subsequent $\mathrm{H}$ elimination reaction from the $\beta$ - $\mathrm{C}$ atom on the substitution site $\left(\mathrm{CS} 16 \rightarrow \mathrm{CS} 10 \_\mathrm{P}+\mathrm{H}, 44.6 \mathrm{kcal} / \mathrm{mol}\right)$ produces CS10_P. Alternatively, product CS7_P forms after the cyclization reaction $(\mathrm{CS} 16 \rightarrow \mathrm{CS} 18,42.1 \mathrm{kcal} / \mathrm{mol})$, intermolecular $\mathrm{H}$ transfer reactions $(\mathrm{CS} 18 \rightarrow \mathrm{CS} 19$, $41.7 \mathrm{kcal} / \mathrm{mol}$ and $\mathrm{CS} 19 \rightarrow \mathrm{CS} 6,37.4 \mathrm{kcal} / \mathrm{mol}$ ), and $\mathrm{H}$ elimination reaction (CS6 $\left.\rightarrow \mathrm{CS} 7 \_\mathrm{P}+\mathrm{H}, 13.8 \mathrm{kcal} / \mathrm{mol}\right) . \mathrm{H}$ migration on the adduct CS2 from the terminal $\mathrm{C}$ atom to the unsaturated $\mathrm{C}$ atom on the $\mathrm{C}_{4} \mathrm{H}_{4}$ substitution leads to the formation of the CS12 structure, with an energy barrier of $58.4 \mathrm{kcal} / \mathrm{mol}(\mathrm{CS} 2 \rightarrow \mathrm{CS} 12)$. This process causes the middle $\mathrm{C}-\mathrm{C}$ double bond to become a $\mathrm{C}-\mathrm{C}$ single bond, and the terminal $\mathrm{C}$ atom becomes active. Benefitted from these features, the subsequent $\mathrm{C}-\mathrm{C}$ rotation reaction $(\mathrm{CS} 12 \rightarrow \mathrm{CS} 13,4.7 \mathrm{kcal} / \mathrm{mol})$ and cyclization reaction $(\mathrm{CS} 13 \rightarrow \mathrm{CS} 6,2.4 \mathrm{kcal} / \mathrm{mol})$ proceed rapidly once CS12 forms, due to the low energy barrier. Here, the intermediate CS13 bridges the product CS17_P and product CS7_P via the channel of $\mathrm{CS} 17 \_\mathrm{P}+\mathrm{H} \rightarrow \mathrm{CS} 13 \rightarrow \mathrm{CS} 6 \rightarrow \mathrm{CS} 7 \_\mathrm{P}+\mathrm{H}$, which proves to be an important conversion channel for $\mathrm{A}_{3}$ formation in the following kinetic analysis.

With these quantum chemistry results, the yields of product in this reaction network were calculated using RRKM theory by solving the master equation. As shown in Fig.3 (a), the formation of products in $\mathrm{A}_{2}-1+\mathrm{C}_{4} \mathrm{H}_{4}$ (C1) reaction system is greatly sensitive to temperature. When the temperature is below $1000 \mathrm{~K}$, the reactions trend toward remaining at the CS2 adduct intermediate due to the relatively high energy barrier in further isomer reactions. At higher temperatures, the main products are $\mathrm{PAH}$ with a $\mathrm{C}_{4} \mathrm{H}_{3}$ radical substitution (CS10_P and CS11_P), and the closed-ring product CS7_P is the minor product. This matches well with the yield distribution 
in phenyl $+\mathrm{C}_{4} \mathrm{H}_{4}$ reaction systems [25]. The results also indicate that it is unreasonable to treat closed-ring products, such as CS7_P as the sole products in a PAH radical $+\mathrm{C}_{4} \mathrm{H}_{4}$ reaction in mechanism [33]. With CS6 or CS14 as the initial well, the mole fraction of the reactant $\left(\mathrm{CS} 7 \_\mathrm{P}+\mathrm{H}\right)$ is still $100 \%$ when the reaction reaches equilibrium, indicating that the formation of CS7_P in this reaction system can be regarded as an irreversible process. On the other hand, the formation of CS10_P and CS11_P is highly reversible. The kinetic characteristics of reactions $\mathrm{CS} 10 \_\mathrm{P}+\mathrm{H} \rightarrow$ products and CS11_P+H $\rightarrow$ products were investigated. In this way, the rate constants of reverse reactions can be evaluated. The results shown in Fig.3 (b)-(c) suggest that CS11_P+H and $\mathrm{A}_{2}-1+\mathrm{C}_{4} \mathrm{H}_{4}$ are the dominant products in CS10_P+H $\rightarrow$ products reaction, and CS10_P+H and $\mathrm{A}_{2}-1+\mathrm{C}_{4} \mathrm{H}_{4}$ are the dominant products in $\mathrm{CS} 11 \_\mathrm{P}+\mathrm{H} \rightarrow$ product reaction. Considering that the conversion between $\mathrm{A}_{2}-1+\mathrm{C}_{4} \mathrm{H}_{4}, \mathrm{CS} 10 \_\mathrm{P}+\mathrm{H}$, and CS11_P+H is a rapid process due to the high reaction rate at flame temperatures, because of its irreversibility, the yield of CS7_P may be higher when the reaction system reaches equilibrium. Evidenced from Fig.3 (a)-(c), the formation of CS17_P+H can be ignored in this reaction network. However, the formation of CS17_P+H is favorable in the following $\mathrm{A}_{2}-1+\mathrm{C}_{4} \mathrm{H}_{4}(\mathrm{C} 4)$ reaction system. The yield distribution of $\mathrm{CS} 17$ - $\mathrm{P}+\mathrm{H} \rightarrow$ products reaction with CS13 as the initial well was examined. The results shown in Fig. 3 (d) confirm that the conversion of CS17_P+H toward CS7_P+H is a rapid process caused by the low energy barrier in the channel $\mathrm{CS} 17 \_\mathrm{P}+\mathrm{H} \rightarrow \mathrm{CS} 13 \rightarrow \mathrm{CS} 6 \rightarrow \mathrm{CS} 7 \_\mathrm{P}+\mathrm{H}$.

\subsection{2 $\mathrm{A}_{2}-1+\mathrm{C}_{4} \mathrm{H}_{4}(\mathrm{C} 4)$ reaction system}

The adduct CS20 forms when the $\mathrm{C} 4$ atom on $\mathrm{C}_{4} \mathrm{H}_{4}$ attaches to $\mathrm{A}_{2}-1$ and splits into four pathways, as shown in Fig.4. Unlike the above $\mathrm{A}_{2}-1+\mathrm{C}_{4} \mathrm{H}_{4}(\mathrm{C} 1)$ reaction system, the $\mathrm{CS} 20$ cannot cyclize to the third six-membered ring (like CS2 $\rightarrow$ CS3 reaction). It produces directly CS17_P by H elimination from the C4 atom on the substitution $\left(\mathrm{CS} 20 \rightarrow \mathrm{CS} 17 \_\mathrm{P}+\mathrm{H}, 44.5 \mathrm{kcal} / \mathrm{mol}\right)$. This provides a competitive pathway for $\mathrm{A}_{3}$ formation, namely $\mathrm{A}_{2}-1+\mathrm{C}_{4} \mathrm{H}_{4}$ $(\mathrm{C} 4) \rightarrow \mathrm{CS} 20 \rightarrow \mathrm{CS} 17 \_\mathrm{P}+\mathrm{H} \rightarrow \mathrm{CS} 13 \rightarrow \mathrm{CS} 6 \rightarrow \mathrm{CS} 7 \_\mathrm{P}+\mathrm{H}$. Alternatively, the other $\mathrm{H}$ elimination from the $\mathrm{C} 4$ atom on the substitution generates the conformer CS65_P species. The energy barrier of CS20 $\rightarrow$ CS65_P+H (44.2 $\mathrm{kcal} / \mathrm{mol}$ ) is close to that of CS20 $\rightarrow \mathrm{CS} 17 \_\mathrm{P}+\mathrm{H}$. The $\mathrm{H}$ transfer from the benzene ring on CS20 to the $\beta-\mathrm{C}$ atom on the $\mathrm{C}_{4} \mathrm{H}_{4}$ substitution is another probable reaction (CS20 $\left.\rightarrow \mathrm{CS} 29,35.1 \mathrm{kcal} / \mathrm{mol}\right)$ with a lower energy barrier, compared to CS20 $\rightarrow \mathrm{CS} 17 \_\mathrm{P}+\mathrm{H}$ reaction. Once formed, CS29 can lead to the formation of CS7_P and a phenanthrenyl radical (CS33) via the pathways of $\mathrm{CS} 29 \rightarrow \mathrm{CS} 30 \rightarrow \mathrm{CS} 31 \rightarrow \mathrm{CS} 32 \rightarrow \mathrm{CS} 7 \_\mathrm{P}+\mathrm{H}$, $\mathrm{CS} 29 \rightarrow \mathrm{CS} 30 \rightarrow \mathrm{CS} 31 \rightarrow \mathrm{CS} 38 \rightarrow \mathrm{CS} 7 \_\mathrm{P}+\mathrm{H}$, and CS29 $\rightarrow \mathrm{CS} 30 \rightarrow \mathrm{CS} 31 \rightarrow \mathrm{CS} 32 \rightarrow \mathrm{CS} 33+\mathrm{H}$. The three pathways are generally similar, and include a C-C rotation reaction $(\mathrm{CS} 29 \rightarrow \mathrm{CS} 30,3.6 \mathrm{kcal} / \mathrm{mol})$, a cyclization reaction $(\mathrm{CS} 30 \rightarrow \mathrm{CS} 31,7.6 \mathrm{kcal} / \mathrm{mol}), \mathrm{H}$ transfer reactions $(\mathrm{CS} 31 \rightarrow \mathrm{CS} 32,41.1 \mathrm{kcal} / \mathrm{mol}$ or $\mathrm{CS} 31 \rightarrow \mathrm{CS} 38,44.5 \mathrm{kcal} / \mathrm{mol})$, $\mathrm{H}$ elimination (CS32 $\rightarrow \mathrm{CS} 7 \_\mathrm{P}+\mathrm{H}, 26.8 \mathrm{kcal} / \mathrm{mol}$ or CS38 $\left.\rightarrow \mathrm{CS} 7 \_\mathrm{P}+\mathrm{H}, 27.9 \mathrm{kcal} / \mathrm{mol}\right)$, and an $\mathrm{H}_{2}$ elimination reaction $\left(\mathrm{CS} 32 \rightarrow \mathrm{CS} 33+\mathrm{H}_{2}, 77.3 \mathrm{kcal} / \mathrm{mol}\right)$. 
Of the three pathways, starting from CS20, the C-C bond rotation reaction of CS20 $\rightarrow$ CS21 occurs with a low energy barrier $(4.7 \mathrm{kcal} / \mathrm{mol})$. The $\mathrm{C}_{4} \mathrm{H}_{4}$ substitution rotates slightly toward the zig-zag surface site of the intermediate CS21, which makes possible the formation of a five-membered ring, though the reaction of $\mathrm{CS} 21 \rightarrow \mathrm{CS} 22(20 \mathrm{kcal} / \mathrm{mol})$, and a six-membered ring though the reaction of $\mathrm{CS} 21 \rightarrow \mathrm{CS} 34(33.7 \mathrm{kcal} / \mathrm{mol})$ possible. The energy barrier of the five-membered ring formation is lower than that of the six-membered ring formation by $13.7 \mathrm{kcal} / \mathrm{mol}$. This means that the formation of the CS22 structure with a five-membered ring may be favorable. The CS22 is a non-planar structure caused by three superfluous $\mathrm{H}$ atoms. The $\mathrm{H}$ elimination and $\mathrm{C}_{2} \mathrm{H}_{2}$ releasing reactions produce more stable chemical structures at flame temperatures. Here, H elimination from the benzene ring gives the product CS37_P. Other $\mathrm{H}$ elimination reactions and $\mathrm{C}_{2} \mathrm{H}_{2}$ releasing reactions for CS22 are studied in the pathways of $\mathrm{CS} 22 \rightarrow \mathrm{CS} 23 \rightarrow \mathrm{CS} 24 \rightarrow \mathrm{CS} 25 \rightarrow \mathrm{CS} 26 \rightarrow \mathrm{CS} 27+\mathrm{H}$ (green dash in Fig.4) and $\mathrm{CS} 22 \rightarrow \mathrm{CS} 23 \rightarrow \mathrm{CS} 28+\mathrm{C}_{2} \mathrm{H}_{2}$ (green dash in Fig.3). The PES of both pathways lie above the others in Fig.4, indicating that the formation of products CS27 and CS28 can be ignored. This is confirmed in the following kinetic analysis.

The yield distribution of products in the $\mathrm{A}_{2}-1+\mathrm{C}_{4} \mathrm{H}_{4}(\mathrm{C} 4)$ reaction system is shown in Fig. 5. Similar to the $\mathrm{A}_{2-}$ $1+\mathrm{C}_{4} \mathrm{H}_{4}(\mathrm{C} 1)$ reaction system, the adduct intermediate CS20 survives with high yield value when the temperature is below $1000 \mathrm{~K}$. At higher temperatures, the main products are CS7_P, CS17_P, CS37_P, and CS65_P in the reaction of $\mathrm{A}_{2}-1+\mathrm{C}_{4} \mathrm{H}_{4}(\mathrm{C} 4)$. The yield of CS7_P, CS17_P, CS37_P, and CS65_P increase rapidly in the temperature range of 800-1300 K; their yield curves are different at higher temperature. The yields of CS17_P and CS65_P increase slightly and converge to $43 \%$ at higher temperatures. In contrast, the yields of CS7_P and CS37_P peak at $1200 \mathrm{~K}$ with values of $11.4 \%$ and $41.4 \%$, respectively, and they decrease linearly in the temperature range of 1200-2500 K. The formation of the minor product CS35_P can be ignored as the yield is less than $0.1 \%$ in the whole temperature region. Once formed, the open-ring products, including CS17_P,CS37_P, and CS65_P, are likely to return to the reaction network with an $\mathrm{H}$ addition, due to high reaction reversibility. As shown in Fig.5 (b)-(d), CS17_P+H, CS37_P+H, and CS65_P+H reactions share similar yield features. The results show that the self-conversion between CS17_P+H, CS37_P+H, and CS65_P+H are preferred, and the formation of CS7_P is only favorable in the temperature range of 1000-1700 K where the yield value is large than 5\%. The conversions from CS17_P+H, CS37_P+H, and CS65_P+H to reactant $\mathrm{A}_{2}-1+\mathrm{C}_{4} \mathrm{H}_{4}$ are kinetically unsupported, and the peak yield value of $\mathrm{A}_{2}-1+\mathrm{C}_{4} \mathrm{H}_{4}$ is only $1 \%$. Combined with the channel $\mathrm{CS} 17 \_\mathrm{P}+\mathrm{H} \rightarrow \mathrm{CS} 13 \rightarrow \mathrm{CS} 6 \rightarrow \mathrm{CS} 7 \_\mathrm{P}+\mathrm{H}$ (shown in Fig. 2), where the CS17_P is quickly consumed to form CS7_P, it can be expected that a significant amount of CS7_P may be converted from other products with the assistance of the $\mathrm{H}$ atom in the entire $\mathrm{A}_{2}-1+\mathrm{C}_{4} \mathrm{H}_{4}(\mathrm{C} 1+\mathrm{C} 4)$ reaction system. 


\subsection{3 $\mathrm{A}_{2}-2+\mathrm{C}_{4} \mathrm{H}_{4}(\mathrm{C1})$ reaction system}

The discussions above focus on reactions with $\mathrm{A}_{2}-1$; here the focus is on reactions with $\mathrm{A}_{2}-2$. The PES of $\mathrm{A}_{2-}$ $2+\mathrm{C}_{4} \mathrm{H}_{4}(\mathrm{C} 1)$ reaction system is shown in Fig.6. When the $\mathrm{C} 1$ atom of $\mathrm{C}_{4} \mathrm{H}_{4}$ attacks the active carbon on the benzene ring, the adduct CS40 forms and splits into six different reaction channels. Two of the six channels lead to the formation of CS54_P and CS55_P via H elimination reactions, those are CS40 $\rightarrow$ CS54_P+H (47.9 kcal/mol) and CS40 $\rightarrow$ CS55_P+H (54.9 kcal/mol). Two other channels, starting from CS40, converge at CS50 with the $\mathrm{C}_{4} \mathrm{H}_{4}$ substitution. Specifically, CS50 forms from the channels of CS40 $\rightarrow$ CS48 $\rightarrow$ CS49 $\rightarrow$ CS50 and CS40 $\rightarrow$ CS50. The former channel involves an $\mathrm{H}$ transfer from the end $\mathrm{C}$ atom to the bare $\mathrm{C}$ atom on the $\mathrm{C}_{4} \mathrm{H}_{4}$ substitution $(\mathrm{CS} 40 \rightarrow \mathrm{CS} 48,35.9 \mathrm{kcal} / \mathrm{mol}), \mathrm{C}-\mathrm{C}$ rotation between benzene moiety and $\mathrm{C}_{4} \mathrm{H}_{4}$ moiety $(\mathrm{CS} 48 \rightarrow \mathrm{CS} 49,4.4$ $\mathrm{kcal} / \mathrm{mol})$, and $\mathrm{H}$ transfer from $\mathrm{C}_{4} \mathrm{H}_{4}$ substitution to the bare $\mathrm{C}$ atom on benzene $(\mathrm{CS} 49 \rightarrow \mathrm{CS} 50,44.5 \mathrm{kcal} / \mathrm{mol}$ ). The latter channel $\mathrm{CS} 40 \rightarrow \mathrm{CS} 50(55.5 \mathrm{kcal} / \mathrm{mol})$ is the $\mathrm{H}$ transfer step occurring on the $\mathrm{C}_{4} \mathrm{H}_{4}$ moiety. In this reaction network, CS50 leads to the formation of the open-ring CS54_P structure and the closed-ring CS7_P structure. The $\mathrm{H}$ elimination reaction $\left(\mathrm{CS} 50 \rightarrow \mathrm{CS} 54 \_\mathrm{P}+\mathrm{H}, 41.4 \mathrm{kcal} / \mathrm{mol}\right)$ generates the product CS54_P. Alternatively, the product CS7_P can form from the channels of CS50 $\rightarrow$ CS51 $\rightarrow$ CS52 $\rightarrow$ CS32 $\rightarrow$ CS7_P+H and $\mathrm{CS} 50 \rightarrow \mathrm{CS} 51 \rightarrow \mathrm{CS} 53 \rightarrow \mathrm{CS} 43 \rightarrow \mathrm{CS} 7 \_\mathrm{P}+\mathrm{H}$, which are featured with a cyclization reaction $(\mathrm{CS} 50 \rightarrow \mathrm{CS} 51,39.9$ $\mathrm{kcal} / \mathrm{mol}$ ), the $\mathrm{H}$ transfer reaction on the benzene ring, and the $\mathrm{H}$ elimination reaction.

The first step in the fifth channel (green line in Fig.6) beginning from CS40, is the H migration on the adduct $\mathrm{CS} 40$ from the terminal $\mathrm{C}$ atom to the bare $\mathrm{C}$ atom on the $\mathrm{C}_{4} \mathrm{H}_{4}$ substitution $(\mathrm{CS} 40 \rightarrow \mathrm{CS} 45,58.5 \mathrm{kcal} / \mathrm{mol})$. The energy barrier and the vibration mode of the transition state in this reaction are almost the same as that in the reaction $\mathrm{CS} 2 \rightarrow \mathrm{CS} 12$ in the $\mathrm{A}_{2}-1+\mathrm{C}_{4} \mathrm{H}_{4}(\mathrm{C} 1)$ reaction system. Once CS45 forms, the rotation of the C-C bond occurs rapidly, due to the low energy barrier $(\mathrm{CS} 45 \rightarrow \mathrm{CS} 46,3.7 \mathrm{kcal} / \mathrm{mol})$. Subsequently, $\mathrm{H}$ elimination from CS46 may produce a CS56_P structure (CS46 $\rightarrow$ CS56_P+H, $44.8 \mathrm{kcal} / \mathrm{mol})$. In terms of the energy barrier, the cyclization reaction $(\mathrm{CS} 46 \rightarrow \mathrm{CS} 47,1.8 \mathrm{kcal} / \mathrm{mol})$ is more likely, followed by the $\mathrm{H}$ elimination reaction $\left(\mathrm{CS} 47 \rightarrow \mathrm{CS} 7 \_\mathrm{P}+\mathrm{H}, 19.9 \mathrm{kcal} / \mathrm{mol}\right)$, to form the more stable structure CS7_P. The last channel, starting from CS40, is labeled as the orange line in Fig. 4. Here, the cyclization reaction (CS40 $\rightarrow \mathrm{CS} 41,41.7 \mathrm{kcal} / \mathrm{mol})$ produces the intermediate CS41, featured with two superfluous $\mathrm{H}$ atoms and a bare $\mathrm{C}$ atom. These features drive the subsequent channels of $\mathrm{CS} 41 \rightarrow \mathrm{CS} 42 \rightarrow \mathrm{CS} 43 \rightarrow \mathrm{CS} 7 \_\mathrm{P}+\mathrm{H}$ and $\mathrm{CS} 41 \rightarrow \mathrm{CS} 31 \rightarrow \ldots \rightarrow \mathrm{CS} 7 \_\mathrm{P}+\mathrm{H}$, consisting of $\mathrm{H}$ transfer reactions and $\mathrm{H}$ elimination reactions.

In the $\mathrm{A}_{2}-2+\mathrm{C}_{4} \mathrm{H}_{4}(\mathrm{C} 1)$ reaction system, the CS54_P and CS55_P species, formed by $\mathrm{H}$ elimination from the adduct intermediate CS40, are the dominant products in the temperature range of 1100-2500 K, as shown in Fig.7 
(a). In this case, the yields of CS7_P and CS56_P are $0.8 \%$ and $0.02 \%$ at $1500 \mathrm{~K}$, indicating that the reactions $\mathrm{A}_{2}-2+\mathrm{C}_{4} \mathrm{H}_{4}(\mathrm{C} 1) \rightarrow \mathrm{CS} 7 \_\mathrm{P}+\mathrm{H}$ and $\mathrm{A}_{2}-2+\mathrm{C}_{4} \mathrm{H}_{4}(\mathrm{C} 1) \rightarrow \mathrm{CS} 56 \_\mathrm{P}+\mathrm{H}$ are too slow to compete with reactions $\mathrm{A}_{2-}$ $2+\mathrm{C}_{4} \mathrm{H}_{4}(\mathrm{C} 1) \rightarrow \mathrm{CS} 54 \_\mathrm{P}+\mathrm{H}$ and $\mathrm{A}_{2}-2+\mathrm{C}_{4} \mathrm{H}_{4}(\mathrm{C} 1) \rightarrow \mathrm{CS} 55 \_\mathrm{P}+\mathrm{H}$. The entrance well in reactions $\mathrm{A}_{2}-2+\mathrm{C}_{4} \mathrm{H}_{4}(\mathrm{C} 1)$ $\rightarrow$ products, CS54_P+H $\rightarrow$ products, and CS55_P+H $\rightarrow$ products are the same (CS40), which is the main reason that the yield distribution is similar in each reaction, as shown in Fig (b)-(c). The results shown in Fig (b)-(c) also indicate that the reaction $\mathrm{A}_{2}-2+\mathrm{C}_{4} \mathrm{H}_{4}(\mathrm{C} 1) \rightarrow \mathrm{CS} 54 \_\mathrm{P}+\mathrm{H}$ and $\mathrm{A}_{2}-2+\mathrm{C}_{4} \mathrm{H}_{4}(\mathrm{C} 1) \rightarrow \mathrm{CS} 55 \_\mathrm{P}+\mathrm{H}$ are highly reversible, evidenced by the high yield of $\mathrm{A}_{2}-2+\mathrm{C}_{4} \mathrm{H}_{4}$ in the reaction of CS54_P+H $\rightarrow$ products and CS55_P+H $\rightarrow$ products. Although the yield of CS56_P is kinetically unsupported, it is still helpful to explore the yield distribution in reaction CS56_P+H $\rightarrow$ products as the species CS56_P has nearly identical structural features as CS17_P. As shown in Fig. (d), CS7_P is the dominant product of the reaction CS56_P+H $\rightarrow$ products in the temperature range studied, resulting from the low energy barrier in the channel of CS56_P+H $\rightarrow$ CS46 $\rightarrow$ CS47 $\rightarrow$ CS7_P+H.

\subsection{4 $\mathrm{A}_{2}-2+\mathrm{C}_{4} \mathrm{H}_{4}(\mathrm{C} 4)$ reaction system}

Generally speaking, the reaction network for the $\mathrm{A}_{2}-2+\mathrm{C}_{4} \mathrm{H}_{4}(\mathrm{C} 4)$ system shown in Fig.8 is similar to that for $\mathrm{A}_{2}-1+\mathrm{C}_{4} \mathrm{H}_{4}$ (C4) (Fig.4) and $\mathrm{A}_{2}-2+\mathrm{C}_{4} \mathrm{H}_{4}$ (C1) (Fig.6) systems. The adduct intermediate CS57 can lead to the formation of CS7_P via the channels of $\mathrm{CS} 57 \rightarrow \mathrm{CS} 58 \rightarrow \mathrm{CS} 45 \rightarrow \ldots \rightarrow \mathrm{CS} 7 \_\mathrm{P}+\mathrm{H}, \mathrm{CS} 57 \rightarrow \mathrm{CS} 59 \rightarrow \mathrm{CS} 58 \rightarrow$ $\mathrm{CS} 45 \rightarrow \ldots \rightarrow \mathrm{CS} 7 \_\mathrm{P}+\mathrm{H}, \quad \mathrm{CS} 57 \rightarrow \mathrm{CS} 61 \rightarrow \mathrm{CS} 62 \rightarrow \mathrm{CS} 43 \rightarrow \ldots \rightarrow \mathrm{CS} 7 \_\mathrm{P}+\mathrm{H}, \quad$ and $\mathrm{CS} 57 \rightarrow \mathrm{CS} 64 \rightarrow \mathrm{CS} 44 \rightarrow \mathrm{CS} 9 \rightarrow \ldots \rightarrow \mathrm{CS} 7 \_\mathrm{P}+\mathrm{H}$, where the $\mathrm{H}$ transfer reactions $(\mathrm{CS} 57 \rightarrow \mathrm{CS} 58,66.7 \mathrm{kcal} / \mathrm{mol}$, $\mathrm{CS} 62 \rightarrow \mathrm{CS} 43,45.5 \mathrm{kcal} / \mathrm{mol}$, and CS9 $\rightarrow \mathrm{CS} 14,46.2 \mathrm{kcal} / \mathrm{mol})$ and rotation of $\mathrm{C}-\mathrm{C}$ double bond $(\mathrm{CS} 58 \rightarrow \mathrm{CS} 45$, $44.8 \mathrm{kcal} / \mathrm{mol}$ ) are the rate limiting steps. The formation of the open-ring structure CS60_P from CS57 is also a reaction possibility, and it is kinetically supported, due to the relatively low energy barrier (CS57 $\rightarrow$ CS60_P, 40.4 $\mathrm{kcal} / \mathrm{mol}$ ) and pathway simplicity. In this reaction system, the $\mathrm{H}$ elimination from ring closure structure CS61 is included, which produces CS63_P, featured with one unsaturated C atom and one superfluous H atom on the same benzene ring. By considering this, it is possible to compare the competitiveness between two reaction pathways. One is the $\mathrm{H}$ elimination from intermediates like CS61 with moderate thermal stability, followed by $\mathrm{H}$ transfer reaction or H elimination to evolve to a structure with higher thermal stability at combustion temperatures. The other pathway is that the $\mathrm{H}$ transfer reaction occurs first, followed by $\mathrm{H}$ elimination, to generate a product like CS7_P.

Compared with other reaction systems, the yield distribution in $\mathrm{A}_{2}-2+\mathrm{C}_{4} \mathrm{H}_{4}(\mathrm{C} 4)$ systems is more concise, as shown in Fig.9 (a)-(b). At flame temperature $\left(\mathrm{T}>1200 \mathrm{~K}\right.$ ), the reaction $\mathrm{A}_{2}-2+\mathrm{C}_{4} \mathrm{H}_{4} \rightarrow$ products mainly produces CS60_P, as shown in Fig.9 (a). In turn, $\mathrm{A}_{2}-2+\mathrm{C}_{4} \mathrm{H}_{4}$ is the dominant product in reaction CS60_P+H $\rightarrow$ products, as 
shown in Fig. 9 (b). The yield of CS63_P is lower than 0.01\%, meaning that the pathway CS61 $\rightarrow$ CS63_P+H $\rightarrow$ steady product is not as competitive as the pathway CS61 $\rightarrow$ intermediate $\rightarrow$ steady product $+\mathrm{H}$.

The formation of anthracene (CS71_P) is also possible in $\mathrm{A}_{2}-2+\mathrm{C}_{4} \mathrm{H}_{4}$ reaction system if the $\mathrm{C}_{4} \mathrm{H}_{4}$ molecule attaches to the active $\mathrm{C}$ atom with a different rotation angle, as shown in Fig. 10. Specifically, CS71_P can be formed from the pathways $\mathrm{A}_{2}-2+\mathrm{C}_{4} \mathrm{H}_{4} \rightarrow \mathrm{CS} 66 \rightarrow \mathrm{CS} 67 \rightarrow \mathrm{CS} 68 \rightarrow \mathrm{CS} 69 \rightarrow \mathrm{CS} 70 \rightarrow \mathrm{CS} 71 \_\mathrm{P}+\mathrm{H}$ and $\mathrm{A}_{2}-2$ $+\mathrm{C}_{4} \mathrm{H}_{4} \rightarrow \mathrm{CS} 72 \rightarrow \mathrm{CS} 73 \rightarrow \mathrm{CS} 74 \rightarrow \mathrm{CS} 75 \rightarrow \mathrm{CS} 76 \rightarrow \mathrm{CS} 70 \rightarrow \mathrm{CS} 71 \_\mathrm{P}+\mathrm{H}$. In the former pathway, the highest energy barrier exists in the $\mathrm{H}$ transfer reaction (CS69 $\rightarrow$ CS70) with the value of $41.6 \mathrm{kcal} / \mathrm{mol}$, which is lower than the energy barrier of corresponding competing reaction $(\mathrm{CS} 69 \rightarrow \mathrm{CS} 68,45.7 \mathrm{kcal} / \mathrm{mol})$. This means that anthracene is likely to form from the $\mathrm{A}_{2}-2+\mathrm{C}_{4} \mathrm{H}_{4} \rightarrow \mathrm{CS} 66 \rightarrow \mathrm{CS} 67 \rightarrow \mathrm{CS} 68 \rightarrow \mathrm{CS} 69 \rightarrow \mathrm{CS} 70 \rightarrow \mathrm{CS} 71 \_\mathrm{P}+\mathrm{H}$ pathway in terms of energy barrier. In contrast, CS71_P formation via the latter pathway is unlikely. The energy barriers of elementary reaction steps, involving the formation of new C-C bond (CS73 $\rightarrow$ CS74, 31.2 kcal/mol) and the dissociation of the existing C-C bond (CS74 $\rightarrow$ CS75, $39.9 \mathrm{kcal} / \mathrm{mol})$, are much higher than that of the corresponding competing reactions $(\mathrm{CS} 73 \rightarrow \mathrm{CS} 72,19.5 \mathrm{kcal} / \mathrm{mol}, \mathrm{CS} 74 \rightarrow \mathrm{CS} 73,36.2 \mathrm{kcal} / \mathrm{mol})$. The yield distribution results support the PES analysis. As shown in Fig. 11 (a) and Fig. 11 (c), anthracene (CS71_P+H) is predominantly formed from the former pathway, especially in the temperature range of 900-1400 K where the yield of CS71_P+H is beyond $5 \%$. Similar to the aforementioned reaction system, the primary products in this reaction system are the CS60_P and CS54_P, which are produced via H-atom abstraction from the intermediates CS66 and CS77, respectively. The secondary H-assisted isomerization of the CS60_P predominantly yields the reactants at high temperature, and produces reactants and anthracene equally around $1000 \mathrm{~K}$ as shown in Fig. 11 (b). This indicates that the anthracene may be the preferred product in $\mathrm{A}_{2}-2+\mathrm{C}_{4} \mathrm{H}_{4}$ reaction system, as compared to phenanthrene in low temperature region. When the temperature is above $1000 \mathrm{~K}$, the secondary H-assisted isomerization CS54_P in this reaction network is unlikely due to the relative lower reaction rate in pathways CS72 $\rightarrow \mathrm{A}_{2}-2+\mathrm{C}_{4} \mathrm{H}_{4}$ and $\mathrm{CS} 72 \rightarrow \mathrm{CS} 73 \rightarrow \mathrm{CS} 74 \rightarrow \mathrm{CS} 75 \rightarrow \mathrm{CS} 76 \rightarrow \mathrm{CS} 70 \rightarrow \mathrm{CS} 71 \_\mathrm{P}+\mathrm{H}$, as shown in Fig. $11(\mathrm{~d})$. It should be noted that secondary $\mathrm{H}$-assisted isomerization of CS54_P is a rapid process via the channel CS54_P+H $\rightarrow$ CS40, as shown in Fig. 6-7.

Apart from the above reaction networks, direct $\mathrm{H}$ abstraction reactions including $\mathrm{A}_{2}-1+\mathrm{C}_{4} \mathrm{H}_{4} \rightarrow \mathrm{A}_{2}+\mathrm{i}-\mathrm{C}_{4} \mathrm{H}_{3}$, $\mathrm{A}_{2}-1+\mathrm{C}_{4} \mathrm{H}_{4} \rightarrow \mathrm{A}_{2}+\mathrm{n}-\mathrm{C}_{4} \mathrm{H}_{3}, \mathrm{~A}_{2}-2+\mathrm{C}_{4} \mathrm{H}_{4} \rightarrow \mathrm{A}_{2}+\mathrm{i}-\mathrm{C}_{4} \mathrm{H}_{3}$, and $\mathrm{A}_{2}-2+\mathrm{C}_{4} \mathrm{H}_{4} \rightarrow \mathrm{A}_{2}+\mathrm{n}-\mathrm{C}_{4} \mathrm{H}_{3}$ were considered as shown in Table S3-S5 in the supplementary materials. Furthermore, a comparison of rate constants for phenyl $+\mathrm{C}_{4} \mathrm{H}_{4} \rightarrow$ benzene+n- $\mathrm{C}_{4} \mathrm{H}_{3}$ [25] and $\mathrm{A}_{2}-2+\mathrm{C}_{4} \mathrm{H}_{4} \rightarrow \mathrm{A}_{2}+n-\mathrm{C}_{4} \mathrm{H}_{3}$ was carried out to extrapolate the rate constants to larger PAH. The rate deviation is within $30 \%$ in the temperature range of 800-2500 K, indicating that the kinetic parameters of $\mathrm{H}$ abstraction reactions are suitable for larger $\mathrm{PAH}$ radical $+\mathrm{C}_{4} \mathrm{H}_{4}$ reaction system. 


\subsection{Kinetic analysis}

\subsubsection{Reaction rate constants}

Based on the quantum chemistry results above, the reaction rate constants were evaluated in the temperature range of 800-2500 K, using RRKM theory with solving master equation. The pressures used are $0.1,1,10$, and $100 \mathrm{~atm}$. The corresponding reaction rate constants are listed in Table 2 in the form of an Arrhenius expression. Verification of this method for calculating rate constants for thermal decomposition reaction and biomolecular addition reactions has been reported in previous studies [7, 35, 53]. Generally, the deviation between calculated rate constants and reported experimental values is within a factor of three at various temperatures and pressures. To the best of our knowledge, there is no experimental data on rate constants for the reaction of $\mathrm{A}_{2}-1\left(\mathrm{~A}_{2}-2\right)+\mathrm{C}_{4} \mathrm{H}_{4}$. Comparisons between $\mathrm{A}_{2}-1\left(\mathrm{~A}_{2}-2\right)+\mathrm{C}_{4} \mathrm{H}_{4}$ and $\mathrm{A}_{1}$ - (phenyl) $+\mathrm{C}_{4} \mathrm{H}_{4}$ were carried out to check the kinetic similarity. The theoretical high-pressure limit rate constant for $\mathrm{A}_{1^{-}}+\mathrm{C}_{4} \mathrm{H}_{4}$ reaction was evaluated by Mebel et al. [25] at the G3(MP2,CC) level. As shown in Fig. 12 (a), the reaction rates of $\mathrm{A}_{2}-1+\mathrm{C}_{4} \mathrm{H}_{4}$ were very close to that of $\mathrm{A}_{2}-2+$ $\mathrm{C}_{4} \mathrm{H}_{4}$, the deviation was within $3 \%$ at $1500 \mathrm{~K}$. This means that the $\mathrm{C}_{4} \mathrm{H}_{4}$ addition to $\mathrm{PAH}$ radical was insensitive to the type of surface site at least for free and zig-zag edges. The rate constants for $\mathrm{A}_{2}-1\left(\mathrm{~A}_{2}-2\right)+\mathrm{C}_{4} \mathrm{H}_{4} \mathrm{were}_{\mathrm{s}}$ also lower than that the $\mathrm{A}_{1^{-}}+\mathrm{C}_{4} \mathrm{H}_{4}$ reaction by a factor of 1.48 at $1500 \mathrm{~K}$. Such deviation was probably due to differences in energy barriers calculated by G3(MP2,CC) and DFT/B3LYP/6-311+G(d,p) methods. As shown in Table S6 of supplementary material, the maximum difference in energy barriers is $2.9 \mathrm{kcal} / \mathrm{mol}$ for the $\mathrm{A}_{2}-2+$ $\mathrm{C}_{4} \mathrm{H}_{4}$ entrance reaction, which may introduce 1.65 time rate coefficient uncertainty at $1500 \mathrm{~K}$. In addition, the different molecular characteristics between phenyl and naphthyl radical could lead to rate deviations. The pressure dependence of the global rate constants is shown in Fig.12 (b). The rate coefficient curves at 0.1, 1, 10, and 100 atm nearly overlap for the reactions $\mathrm{A}_{2}-1+\mathrm{C}_{4} \mathrm{H}_{4}\left(\mathrm{C}_{1}\right) \rightarrow \mathrm{CS} 10 \_\mathrm{P}+\mathrm{H}, \mathrm{A}_{2}-1+\mathrm{C}_{4} \mathrm{H}_{4}\left(\mathrm{C}_{1}\right) \rightarrow \mathrm{CS} 11 \_\mathrm{P}+\mathrm{H}$, and A $2-$ $1+\mathrm{C}_{4} \mathrm{H}_{4}\left(\mathrm{C}_{1}\right) \rightarrow \mathrm{CS} 7 \_\mathrm{P}+\mathrm{H}$, respectively. Similar pressure behavior was also observed in $\mathrm{A}_{2}-1+\mathrm{C}_{4} \mathrm{H}_{4}\left(\mathrm{C}_{4}\right), \mathrm{A}_{2-}$ $2+\mathrm{C}_{4} \mathrm{H}_{4}\left(\mathrm{C}_{1}\right)$, and $\mathrm{A}_{2}-2+\mathrm{C}_{4} \mathrm{H}_{4}\left(\mathrm{C}_{4}\right)$ reaction systems. Therefore, it can be concluded that the rate constants of $\mathrm{PAH}$ radical $+\mathrm{C}_{4} \mathrm{H}_{4} \rightarrow$ product $+\mathrm{H}$ type reaction are nearly independent of pressure.

\subsubsection{Yield distribution in $0-\mathrm{D}$ reactor}

The yield distributions of products were discussed with PES analysis for each sub-system above. Due to the high reversibility of some reactions, it was necessary to examine the yield distribution in the entire $\mathrm{A}_{2}-\mathrm{H}_{-}-\mathrm{C}_{4} \mathrm{H}_{4}-\mathrm{H}_{2}-\mathrm{N}_{2}$ $\left(\mathrm{A}_{2}, \mathrm{H}, \mathrm{C}_{4} \mathrm{H}_{4}, \mathrm{H}_{2}, \mathrm{~N}_{2}\right.$ are the reactant) reaction system, including all reactions listed in Table 2. As shown in Fig. 11, the yield distribution was highly sensitive to the 0-D reactor temperature. The low yield of $\mathrm{A}_{3}$ indicated that $\mathrm{A}_{3}$ formation was unlikely to occur in the $\mathrm{A}_{2}-\mathrm{H}-\mathrm{C}_{4} \mathrm{H}_{4}-\mathrm{H}_{2}-\mathrm{N}_{2}$ reaction framework at $1000 \mathrm{~K}$, and adduct 
intermediates CS2 and CS40 were the main products, as illustrated in Fig .13 (a); this is because the energy barriers of $\mathrm{H}$ elimination reactions and isomer reactions from CS2 and CS40 species were relatively high. The formation of $\mathrm{A}_{3}$ and $\mathrm{PAH}$ with $\mathrm{C}_{4} \mathrm{H}_{3}$ radical substitutions are more favorable at higher temperatures. As shown in Fig. 13 (b)-(d), the mole fractions of $\mathrm{A}_{3}$ and $\mathrm{PAH}$ with $\mathrm{C}_{4} \mathrm{H}_{3}$ radical substitution CS10_P were close, and the values top two among all intermediates and products when the temperature was higher than $1250 \mathrm{~K}$. The results confirmed the above analysis, that the yield of $\mathrm{A}_{3}$ may be high in the entire $\mathrm{A}_{2}-\mathrm{H}-\mathrm{C}_{4} \mathrm{H}_{4}-\mathrm{H}_{2}-\mathrm{N}_{2}$ reaction system because its reaction rate is irreversible. The predicted yield distribution of products at $1500 \mathrm{~K}$ is in good agreement with the experimental results for the naphthyl radical $+\mathrm{C}_{4} \mathrm{H}_{4}$ reaction, obtained at $1450 \pm 10 \mathrm{~K}$, where the mass peak of dominant product was 178 (CS10_P and $\mathrm{A}_{3}$ ). It is also observed that the concentration ratio between phenanthrene $\left(\mathrm{A}_{3}\right)$ and anthracene (CS71_P) increases at higher temperature. For example, the ratio is equal to 1.2 at $1000 \mathrm{~K}$ and increases to 18.2 at $1750 \mathrm{~K}$. This is consistent with the PAH experimental results showing that the concentration of anthracene in sooting flame is negligible when compared to phenanthrene [17, 27].

The $\mathrm{A}_{3}$ formation by $\mathrm{A}_{2}-1+\mathrm{C}_{4} \mathrm{H}_{4} \rightarrow \mathrm{A}_{3}+\mathrm{H}$ and $\mathrm{A}_{2}-2+\mathrm{C}_{4} \mathrm{H}_{4} \rightarrow \mathrm{A}_{3}+\mathrm{H}$ reactions in PAHs mechanism proposed by Wang et al. [33] and Chernov et al. [28] are discussed here to test the robustness of the rate constants used in the mechanism. As shown in Fig. 13 (a)-(d), the predicted mole fraction of $\mathrm{A}_{3}$, using reference rate constants [28, 33], was less sensitive to temperature. For example, the mole fraction of $\mathrm{A}_{3}$ predicted with the rate constant suggested by Chernov et al. at $1750 \mathrm{~K}$, was higher than that at $1000 \mathrm{~K}$ by 6.06 times. However, the gap was as great as 165 times in this study. The second feature is that the rate constants used in the PAH mechanism were significantly higher, especially at low temperatures. For example, the mole fraction of $\mathrm{A}_{3}$, predicted with the rate constant suggested by Chernov et al., was higher than the rate constants reported here by a factor of $88.7,17.8$, 6.3 , and 3.3 at 1000, 1250, 1500, and $1750 \mathrm{~K}$, respectively.

As discussed in the PES analysis, the reaction pathway was significantly different when $\mathrm{C}_{4} \mathrm{H}_{4}$ attacks the bare $C$ atom near the free edge $\left(A_{2}-2\right)$ and zig-zag edge surface sites $\left(A_{2}-1\right)$. To check the site effect on $A_{3}$ formation in such a reaction system, the sensitivity of $A_{3}$ formation was performed. Each specific reaction network is individually removed from the entire reaction system; then the importance of the specific reaction network can be evaluated by comparing the mole fractions of $\mathrm{A}_{3}$ calculated with and without removing the specific reaction network. As shown in Fig.14, the calculated mole fraction of $\mathrm{A}_{3}$, removing the $\mathrm{A}_{2}-1+\mathrm{C}_{4} \mathrm{H}_{4}$ reaction network (shown in Fig.2 and Fig.4) is lower by 73.3\% than when no reaction is removed. The value becomes $16.2 \%$ when the $\mathrm{A}_{2}-2+\mathrm{C}_{4} \mathrm{H}_{4}$ reaction network (shown in Fig.6 and Fig.8) is removed. Therefore, $\mathrm{A}_{2}-1+\mathrm{C}_{4} \mathrm{H}_{4} \rightarrow \mathrm{A}_{3}+\mathrm{H}$ (zigzag edge) is the main pathway leading to $\mathrm{A}_{3}$ formation, instead of $\mathrm{A}_{2}-2+\mathrm{C}_{4} \mathrm{H}_{4} \rightarrow \mathrm{A}_{3}+\mathrm{H}$ (free edge). In other words, the new benzene ring is more likely to form near the zig-zag edge surface site. In addition, the $\mathrm{A}_{2}-1+$ $\mathrm{C}_{4} \mathrm{H}_{4} \rightarrow \mathrm{A}_{3}+\mathrm{H}$ and $\mathrm{A}_{2}-2+\mathrm{C}_{4} \mathrm{H}_{4} \rightarrow \mathrm{A}_{3}+\mathrm{H}$ reactions were removed, and only 5.4\% reduction was observed. This indicates that the majority of $\mathrm{A}_{3}(94.6 \%)$ is generated by a rapid and effective conversion from other products 
and intermediates, further confirmed the analysis that an accumulated total yield of $\mathrm{A}_{3}$ may be high due to the irreversibility of the $\mathrm{A}_{3}+\mathrm{H}$ reaction and the high reversibility of other products $+\mathrm{H}$ reactions.

The PAH kinetics module is rapidly being employed in transportation fuel mechanisms for soot prediction, but due to computational costs, it is necessary to simplify the reaction pathways for engine CFD simulations. With the above strategy, the sensitivity analysis for each $\mathrm{A}_{3}$ formation pathway was carried out for pathway simplification. The results, shown in Fig. S3-S4 in supplementary material, indicate that the pathways linked to CS10_P, CS17_P, CS37_P, CS60_P, and CS65_P should be maintained to describe the formation of A3, and that other pathways can be ignored. The reaction pathways filtered by sensitivity analysis are marked with an asterisk in Table 1. The fitted rate constants for one-step $A_{3}$ formation process $\left(A_{2}-1+C_{4} H_{4} \rightarrow A_{3}+H\right.$ and $A_{2}-$ $2+\mathrm{C}_{4} \mathrm{H}_{4} \rightarrow \mathrm{A}_{3}+\mathrm{H}$ reactions) are provided in Table $\mathrm{S} 2$ in the supplementary material.

\subsubsection{Discussion on analogous treatment of kinetics}

To extend the kinetic rate parameters to the larger $\mathrm{PAH}$ radical $+\mathrm{C}_{4} \mathrm{H}_{4}$ reaction system, the formation of $\mathrm{A}_{2}$ from the $\mathrm{A}_{1}-\mathrm{H}-\mathrm{C}_{4} \mathrm{H}_{4}-\mathrm{H}_{2}-\mathrm{N}_{2}$ reaction system, and $\mathrm{A}_{3}$ from the $\mathrm{A}_{2}-\mathrm{H}-\mathrm{C}_{4} \mathrm{H}_{4}-\mathrm{H}_{2}-\mathrm{N}_{2}$ reaction system, are discussed here. The corresponding kinetic parameters used in the $\mathrm{A}_{1}-\mathrm{H}-\mathrm{C}_{4} \mathrm{H}_{4}-\mathrm{H}_{2}-\mathrm{N}_{2}$ reaction systems are listed in Table 1. In simulations, the mole fractions of the $\mathrm{A}_{1}, \mathrm{H}$, and $\mathrm{C}_{4} \mathrm{H}_{4}$ in the $\mathrm{A}_{1}-\mathrm{H}_{-}-\mathrm{C}_{4} \mathrm{H}_{4}-\mathrm{H}_{2}-\mathrm{N}_{2}$ reaction system are the same as that of $\mathrm{A}_{2}, \mathrm{H}$, and $\mathrm{C}_{4} \mathrm{H}_{4}$ in the $\mathrm{A}_{2}-\mathrm{H}-\mathrm{C}_{4} \mathrm{H}_{4}-\mathrm{H}_{2}-\mathrm{N}_{2}$ reaction system. In this way, it is possible to compare the concentration of $\mathrm{A}_{2}$ formed in $\mathrm{A}_{1}-\mathrm{H}-\mathrm{C}_{4} \mathrm{H}_{4}-\mathrm{H}_{2}-\mathrm{N}_{2}$ reaction system with that of $\mathrm{A}_{3}$ formed in $\mathrm{A}_{2}-\mathrm{H}-\mathrm{C}_{4} \mathrm{H}_{4}-\mathrm{H}_{2}-\mathrm{N}_{2}$ reaction system, to check the kinetic dependence along with reactant size. The kinetic features of the two process are generally similar, as shown in Fig. 15. A forms more quickly than $\mathrm{A}_{2}$ by a factor of 2.9 at $1000 \mathrm{~K}$, and it is slower than $\mathrm{A}_{2}$ by a factor of 1.5 and 2.2 at $1500 \mathrm{~K}$ and $2000 \mathrm{~K}$. The deviation may be the results of slightly different rate constants, as discussed above for Fig. 10 (a). Also, the formation of other $\mathrm{A}_{2}$ isomers was not considered in the $\mathrm{A}_{1}-\mathrm{H}-\mathrm{C}_{4} \mathrm{H}_{4}-\mathrm{H}_{2}-\mathrm{N}_{2}$ reaction systems, but the formation of all $\mathrm{A}_{3}$ isomers was considered in the $\mathrm{A}_{2}-\mathrm{H}-\mathrm{C}_{4} \mathrm{H}_{4}-\mathrm{H}_{2}-\mathrm{N}_{2}$ reaction systems. This may be a potential reason for the deviation at $1500 \mathrm{~K}$ and $2000 \mathrm{~K}$, where the formation of corresponding isomers was favored. Therefore, it can be inferred that the analogous treatment of rate constants is acceptable in the larger $\mathrm{PAH}$ radical $+\mathrm{C}_{4} \mathrm{H}_{4}$ reaction system, as the reaction rate calculation error is nearly within a factor of three due to the energy accuracy (as shown in Table S6 and Fig. S5 in the supplementary material) and uncertainty in MultiWell.

\section{Conclusions}

This study systematically investigated the possibilities of the formation of phenanthrene and $\mathrm{PAH}$ with a $\mathrm{C}_{4} \mathrm{H}_{3}$ radical substitution, through the reaction of a naphthyl radical and vinylacetylene $\left(\mathrm{C}_{4} \mathrm{H}_{4}\right)$. Potential energy 
surfaces were obtained from the combination of DFT/B3LYP/6-311+G(d,p), CCSD/6-311+G(d,p), and CBSQB3 methods. The reaction rate constants at 0.1-100 atm were evaluated by the RRKM theory with solving master equation in the temperature range of 800-2500 K. The yield distribution was investigated in a 0 -D batch reactor. Finally, the reaction pathway analysis and analogous treatment of rate constants toward a larger PAH radical + $\mathrm{C}_{4} \mathrm{H}_{4}$ reaction system were discussed. The following conclusions can be made:

The potential energy surfaces show that the products including phenanthrene, anthracene, PAH with a fivemembered ring structure, and $\mathrm{PAH}$ with a $\mathrm{C}_{4} \mathrm{H}_{3}$ radical substitution can be formed in $\mathrm{A}_{2}-1+\mathrm{C}_{4} \mathrm{H}_{4}$ and $\mathrm{A}_{2}-2+\mathrm{C}_{4} \mathrm{H}_{4}$ reaction systems. The $\mathrm{PAH}$ with a $\mathrm{C}_{4} \mathrm{H}_{3}$ radical substitution can be generated by one step $\mathrm{H}$ elimination reaction from the adduct intermediate. The formation of phenanthrene, anthracene, and PAH with five-membered rings is a multistep reaction process. The yield distribution in each sub-reaction system suggests that the $\mathrm{PAH}$ with a $\mathrm{C}_{4} \mathrm{H}_{3}$ radical substitution is more likely to form due to the relatively low energy barrier in the formation pathways, but the corresponding reversible reactions ( $\mathrm{H}$ addition reaction) occur rapidly at flame temperature.

Kinetic results revealed that the rate constants of the bimolecular $\mathrm{A}_{2}-1\left(\mathrm{~A}_{2}-2\right)+\mathrm{C}_{4} \mathrm{H}_{4} \rightarrow$ product $+\mathrm{H}$ reaction are pressure-independent. The yield distribution in a 0-D batch reactor indicated that phenanthrene and PAH with $\mathrm{C}_{4} \mathrm{H}_{3}$ radical substitution are the main products when the temperature is higher than $1000 \mathrm{~K}$. The existence of abundant $\mathrm{PAH}$ with a $\mathrm{C}_{4} \mathrm{H}_{3}$ radical substitution at flame temperatures supports (to some extent), the chemicalcoalescence nucleation pathway driven by PAHs with a radical substitution.

For the development of PAH mechanisms, sensitivity analysis was performed to reduce the reaction pathways. The results showed that the pathways linked to products CS11_P, CS35_P, CS54_P, CS55_P, CS56_P and CS63_P could be removed from the reaction network. Comparisons between the formation rate of $A_{2}$ from phenyl $+\mathrm{C}_{4} \mathrm{H}_{4}$ reactions and the formation rate of $\mathrm{A}_{3}$ from naphthyl radical $+\mathrm{C}_{4} \mathrm{H}_{4}$ reactions were discussed. Their formation rates were similar, indicating that the analogous treatment of rate constants from $\mathrm{A}_{2}-1\left(\mathrm{~A}_{2}-2\right)+\mathrm{C}_{4} \mathrm{H}_{4}$ reactions to larger $\mathrm{PAH}$ radical $+\mathrm{C}_{4} \mathrm{H}_{4}$ reaction is reasonable.

\section{Acknowledgments}

This research was supported by the Clean Combustion Research Center at the King Abdullah University of Science and Technology (KAUST). The work at Shanghai Jiao Tong University was supported by National Natural Science Foundation of China (91441129) and the 111 Project (B13018).

\section{Supplementary materials}


The T1 diagnostic values, effect of collision energy transfer on the branching ratio of products, IRC analysis, sensitivity analysis of reaction pathways leading to $A_{3}$ formation, reaction rate parameters for one-step $A_{3}$ formation process and direct $\mathrm{H}$ abstraction reactions, rate uncertainty analysis, energies, vibrational frequencies (1-D hindered rotation), rotational constants, external symmetry number, optical isomers, electronic ground state, Lennard-Jones parameters for all optimized structures were provided in supplementary material.

\section{Reference}

[1] D.V. Krasnikov, V.L. Kuznetsov, A.I. Romanenko, A.N. Shmakov, Side reaction in catalytic CVD growth of carbon nanotubes: Surface pyrolysis of a hydrocarbon precursor with the formation of lateral carbon deposits, Carbon 139 (2018) 105-117.

[2] G.-B. Zheng, H. Sano, Y. Uchiyama, A layer-by-layer deposition mechanism for producing a pyrolytic carbon coating on carbon nanotubes, Carbon 57 (2013) 267-273.

[3] A. Beitollahi, M.A.S. Sheikhaleslami, A novel approach for development of graphene structure in mesoporous carbon of high specific surface area, Carbon 107 (2016) 440-447.

[4] K.J. MacKenzie, O.M. Dunens, A.T. Harris, An updated review of synthesis parameters and growth mechanisms for carbon nanotubes in fluidized beds, Ind. Eng. Chem. Res. 49 (2010) 5323-5338.

[5] V. Jourdain, C. Bichara, Current understanding of the growth of carbon nanotubes in catalytic chemical vapour deposition, Carbon 58 (2013) 2-39.

[6] Y. An, M. Jaasim, R. Vallinayagam, S. Vedharaj, H.G. Im, B. Johansson, Numerical simulation of combustion and soot under partially premixed combustion of low-octane gasoline, Fuel 211 (2018) 420-431.

[7] P. Liu, Y. Zhang, L. Wang, B. Tian, B. Guan, D. Han, Z. Huang, H. Lin, The chemical mechanism of exhaust gas recirculation on polycyclic aromatic hydrocarbons formation based on LIF measurement, Energ. Fuels (2018).

[8] H. Wang, Formation of nascent soot and other condensed-phase materials in flames, Proc. Combust. Inst 33 (2011) 41-67.

[9] Y.-z. An, Y.-q. Pei, J. Qin, H. Zhao, S.-p. Teng, B. Li, X. Li, Development of a PAH (polycyclic aromatic hydrocarbon) formation model for gasoline surrogates and its application for GDI (gasoline direct injection) engine CFD (computational fluid dynamics) simulation, Energy 94 (2016) 367-379.

[10] Y.-z. An, S.-p. Teng, Y.-q. Pei, J. Qin, X. Li, H. Zhao, An experimental study of polycyclic aromatic hydrocarbons and soot emissions from a GDI engine fueled with commercial gasoline, Fuel 164 (2016) $160-171$. [11] K.O. Johansson, M.P. Head-Gordon, P.E. Schrader, K.R. Wilson, H.A. Michelsen, Resonance-stabilized hydrocarbon-radical chain reactions may explain soot inception and growth, Science 361 (2018) 997-1000.

[12] L. Zhao, R.I. Kaiser, B. Xu, U. Ablikim, M. Ahmed, D. Joshi, G. Veber, F.R. Fischer, A.M. Mebel, Pyrene synthesis in circumstellar envelopes and its role in the formation of 2D nanostructures, Nat. Astron. 2 (2018) 413419.

[13] H. Wang, M. Frenklach, Calculations of rate coefficients for the chemically activated reactions of acetylene with vinylic and aromatic radicals, J. Phys. Chem. 98 (1994) 11465-11489.

[14] A.M. Mebel, Y. Georgievskii, A.W. Jasper, S.J. Klippenstein, Temperature- and pressure-dependent rate coefficients for the HACA pathways from benzene to naphthalene, Proc. Combust. Inst 36 (2017) 919-926.

[15] D.S. Parker, R. Kaiser, B. Bandyopadhyay, O. Kostko, T.P. Troy, M. Ahmed, Unexpected chemistry from the reaction of naphthyl and acetylene at combustion-like temperatures, Angew. Chem. Int. Edit 127 (2015) 55115514.

[16] P. Liu, Z. Li, A. Bennett, H. Lin, S.M. Sarathy, W.L. Roberts, The Site Effect on PAHs Formation in HACAbased Mass Growth Process, Combust. Flame 199 (2019) 54-68. 
[17] M.J. Castaldi, N.M. Marinov, C.F. Melius, J. Huang, S.M. Senkan, W.J. Pit, C.K. Westbrook, Experimental and modeling investigation of aromatic and polycyclic aromatic hydrocarbon formation in a premixed ethylene flame, Proc. Combust. Inst 26 (1996) 693-702.

[18] A. Raj, M.J. Al Rashidi, S.H. Chung, S.M. Sarathy, PAH growth initiated by propargyl addition: mechanism development and computational kinetics, J. Phys. Chem. A 118 (2014) 2865-2885.

[19] J. Yang, L. Zhao, W. Yuan, F. Qi, Y. Li, Experimental and kinetic modeling investigation on laminar premixed benzene flames with various equivalence ratios, Proc. Combust. Inst 35 (2015) 855-862.

[20] Y. Li, C. Huang, L. Wei, B. Yang, J. Wang, Z. Tian, T. Zhang, L. Sheng, F. Qi, An Experimental Study of Rich Premixed Gasoline/O $2 /$ Ar Flame with Tunable Synchrotron Vacuum Ultraviolet Photoionization, Energ. Fuels 21 (2007) 1931-1941.

[21] P. Liu, H. Lin, Z. He, Y. Zhang, B. Guan, Z. Huang, The mechanism and kinetic analysis of $\mathrm{C}_{4} \mathrm{H}_{4}+\mathrm{C}_{4} \mathrm{H}_{4}$ (but-1-ene-3-yne) reaction with features of H-transfer in combustion, Int. J. Hydrogen Energ. 41 (2016) 32493258.

[22] C. Shao, H. Wang, N. Atef, Z. Wang, B. Chen, M. Almalki, Y. Zhang, C. Cao, J. Yang, S.M. Sarathy, Polycyclic aromatic hydrocarbons in pyrolysis of gasoline surrogates (n-heptane/iso-octane/toluene), Proc. Combust. Inst (2018), doi: 10. 1016/j.proci.2018.06.087.

[23] K. Norinaga, O. Deutschmann, K.J. Hüttinger, Analysis of gas phase compounds in chemical vapor deposition of carbon from light hydrocarbons, Carbon 44 (2006) 1790-1800.

[24] D.S. Parker, F. Zhang, Y.S. Kim, R.I. Kaiser, A. Landera, V.V. Kislov, A.M. Mebel, A. Tielens, Low temperature formation of naphthalene and its role in the synthesis of PAHs (polycyclic aromatic hydrocarbons) in the interstellar medium, P. Natl. Acad. Sci. 109 (2012) 53-58.

[25] A.M. Mebel, A. Landera, R.I. Kaiser, Formation mechanisms of naphthalene and indene: from the interstellar medium to combustion flames, J. Phys. Chem. A 121 (2017) 901-926.

[26] L. Zhao, R.I. Kaiser, B. Xu, U. Ablikim, M. Ahmed, M.V. Zagidullin, V.N. Azyazov, A.H. Howlader, S.F. Wnuk, A.M. Mebel, VUV Photoionization Study of the Formation of the Simplest Polycyclic Aromatic Hydrocarbon: Naphthalene $\left(\mathrm{C}_{10} \mathrm{H}_{8}\right)$, J. Phys. Chem. Lett. 9 (2018) 2620-2626.

[27] J. Appel, H. Bockhorn, M. Frenklach, Kinetic modeling of soot formation with detailed chemistry and physics: laminar premixed flames of $\mathrm{C}_{2}$ hydrocarbons, Combust. Flame 121 (2000) 122-136.

[28] V. Chernov, M.J. Thomson, S.B. Dworkin, N.A. Slavinskaya, U. Riedel, Soot formation with C1 and C2 fuels using an improved chemical mechanism for PAH growth, Combust. Flame 161 (2014) 592-601.

[29] N.W. Moriarty, M. Frenklach, AB initio study of naphthalene formation by addition of vinylacetylene to phenyl, Proc. Combust. Inst 28 (2000) 2563-2568.

[30] Y. Ra, R.D. Reitz, A reduced chemical kinetic model for IC engine combustion simulations with primary reference fuels, Combust. Flame 155 (2008) 713-738.

[31] Y.-z. An, Y.-q. Pei, J. Qin, H. Zhao, X. Li, Kinetic modeling of polycyclic aromatic hydrocarbons formation process for gasoline surrogate fuels, Energ. Convers. Manage. 100 (2015) 249-261.

[32] B. Pang, M.-Z. Xie, M. Jia, Y.-D. Liu, Development of a Phenomenological Soot Model Coupled with a Skeletal PAH Mechanism for Practical Engine Simulation, Energ. Fuels 27 (2013) 1699-1711.

[33] Y. Wang, A. Raj, S.H. Chung, A PAH growth mechanism and synergistic effect on PAH formation in counterflow diffusion flames, Combust. Flame 160 (2013) 1667-1676.

[34] J. Aguilera-Iparraguirre, W. Klopper, Density Functional Theory Study of the Formation of Naphthalene and Phenanthrene from Reactions of Phenyl with Vinyl- and Phenylacetylene, J. Chem. Theory Comput. 3 (2007) 139-145.

[35] P. Liu, H. Lin, Y. Yang, C. Shao, C. Gu, Z. Huang, New insights into thermal decomposition of polycyclic aromatic hydrocarbon oxyradicals, J. Phys. Chem. A 118 (2014) 11337-11345.

[36] M. Frenklach, Z. Liu, R.I. Singh, G.R. Galimova, V.N. Azyazov, A.M. Mebel, Detailed, sterically-resolved modeling of soot oxidation: Role of $\mathrm{O}$ atoms, interplay with particle nanostructure, and emergence of inner particle burning, Combust. Flame 188 (2018) 284-306. 
[37] A. Semenikhin, A. Savchenkova, I. Chechet, S. Matveev, Z. Liu, M. Frenklach, A. Mebel, Rate constants for $\mathrm{H}$ abstraction from benzo (a) pyrene and chrysene: a theoretical study, Phys. Chem. Chem. Phys. 19 (2017) 25401-25413.

[38] H. Zhang, J. Liu, J. Shen, X. Jiang, Thermodynamic and kinetic evaluation of the reaction between NO (nitric oxide) and char(N) (char bound nitrogen) in coal combustion, Energy 82 (2015) 312-321.

[39] H. Zhang, J. Liu, X. Wang, X. Jiang, Density functional theory study on two different oxygen enhancement mechanisms during NO-char interaction, Combust. Flame 169 (2016) 11-18.

[40] L. Zhao, R.I. Kaiser, B. Xu, U. Ablikim, M. Ahmed, M.M. Evseev, E.K. Bashkirov, V.N. Azyazov, A.M. Mebel, Low-temperature formation of polycyclic aromatic hydrocarbons in Titan's atmosphere, Nat. Astron. doi:10.1038/s41550-018-0585-y(2018).

[41] H. Zhang, X. Jiang, J. Liu, J. Shen, New insights into the heterogeneous reduction reaction between NO and char-bound nitrogen, Ind. Eng. Chem. Res. 53 (2014) 6307-6315.

[42] H. Li, G. Henkelman, Dehydrogenation Selectivity of Ethanol on Close-Packed Transition Metal Surfaces: A Computational Study of Monometallic, Pd/Au, and Rh/Au Catalysts, J. Phys. Chem. C 121 (2017) 2750427510.

[43] H. Li, L. Luo, P. Kunal, C.S. Bonifacio, Z. Duan, J.C. Yang, S.M. Humphrey, R.M. Crooks, G. Henkelman, Oxygen Reduction Reaction on Classically Immiscible Bimetallics: A Case Study of RhAu, J. Phys. Chem. C 122 (2018) 2712-2716.

[44] R.D. Johnson, NIST computational chemistry comparison and benchmark database, National Institute of Standards and Technology: Gaithersburg, MD, 2005.

[45] E.K. Pokon, M.D. Liptak, S. Feldgus, G.C. Shields, Comparison of CBS-QB3, CBS-APNO, and G3 predictions of gas phase deprotonation data, J. Phys. Chem. A 105 (2001) 10483-10487.

[46] T.J. Lee, P.R. Taylor, A diagnostic for determining the quality of single-reference electron correlation methods, Int. J. Quantum Chem. 36 (1989) 199-207.

[47] J.C. Rienstra-Kiracofe, W.D. Allen, H.F. Schaefer, The $\mathrm{C}_{2} \mathrm{H}_{5}+\mathrm{O}_{2}$ reaction mechanism: high-level ab initio characterizations, J. Phys. Chem. A 104 (2000) 9823-9840.

[48] P. Peter, A perspective on the CASPT2 method, Int. J. Quantum Chem. 111 (2011) 3273-3279.

[49] H. Hippler, J. Troe, H. Wendelken, Collisional deactivation of vibrationally highly excited polyatomic molecules. II. Direct observations for excited toluene, J. Chem. Phys. 78 (1983) 6709-6717.

[50] J. Zador, A.W. Jasper, J.A. Miller, The reaction between propene and hydroxyl, Phys. Chem. Chem. Phys. 11 (2009) 11040-11053.

[51] H. Wang, M. Frenklach, Transport properties of polycyclic aromatic hydrocarbons for flame modeling, Combust. flame 96 (1994) 163-170.

[52] W.T. Duncan, R.L. Bell, T.N. Truong, TheRate: Program for ab initio direct dynamics calculations of thermal and vibrational-state-selected rate constants, J. Comput. Chem. 19 (1998) 1039-1052.

[53] P. Liu, H. Lin, Y. Yang, C. Shao, B. Guan, Z. Huang, Investigating the Role of $\mathrm{CH}_{2}$ Radicals in the HACA Mechanism, J. Phys. Chem. A 119 (2015) 3261-3268. 


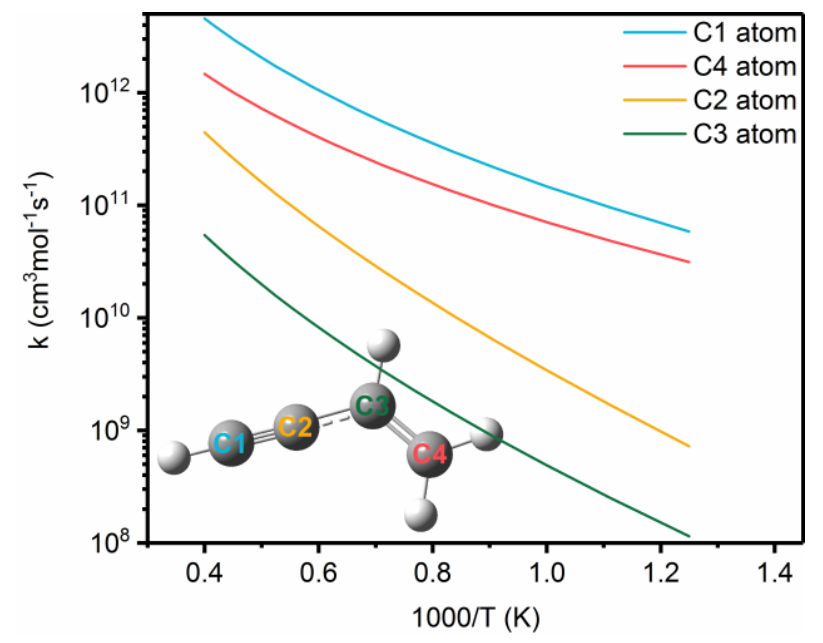

(a)

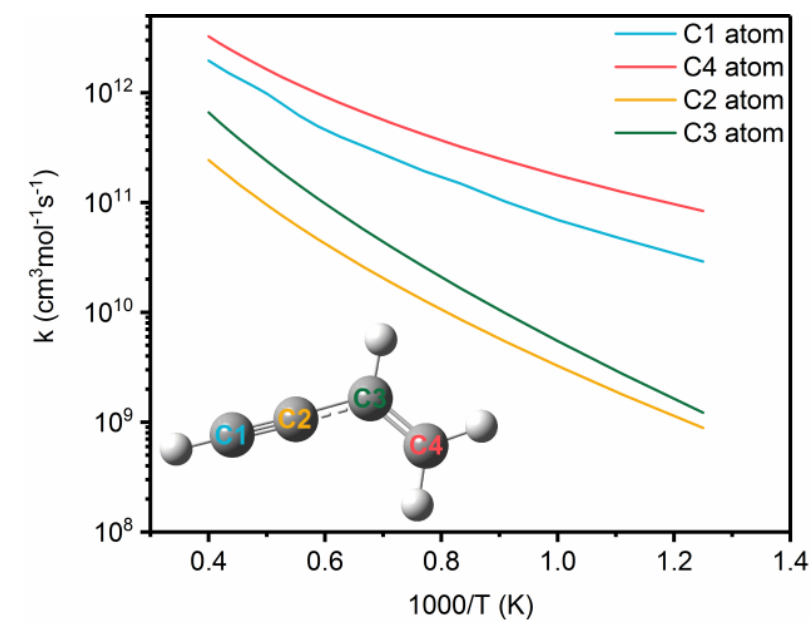

(b)

Fig. 1 Rate constants of $\mathrm{C}_{4} \mathrm{H}_{4}$ attaching to $\mathrm{A}_{2}-1$ (a) and $\mathrm{A}_{2}-2$ (b) reaction steps.

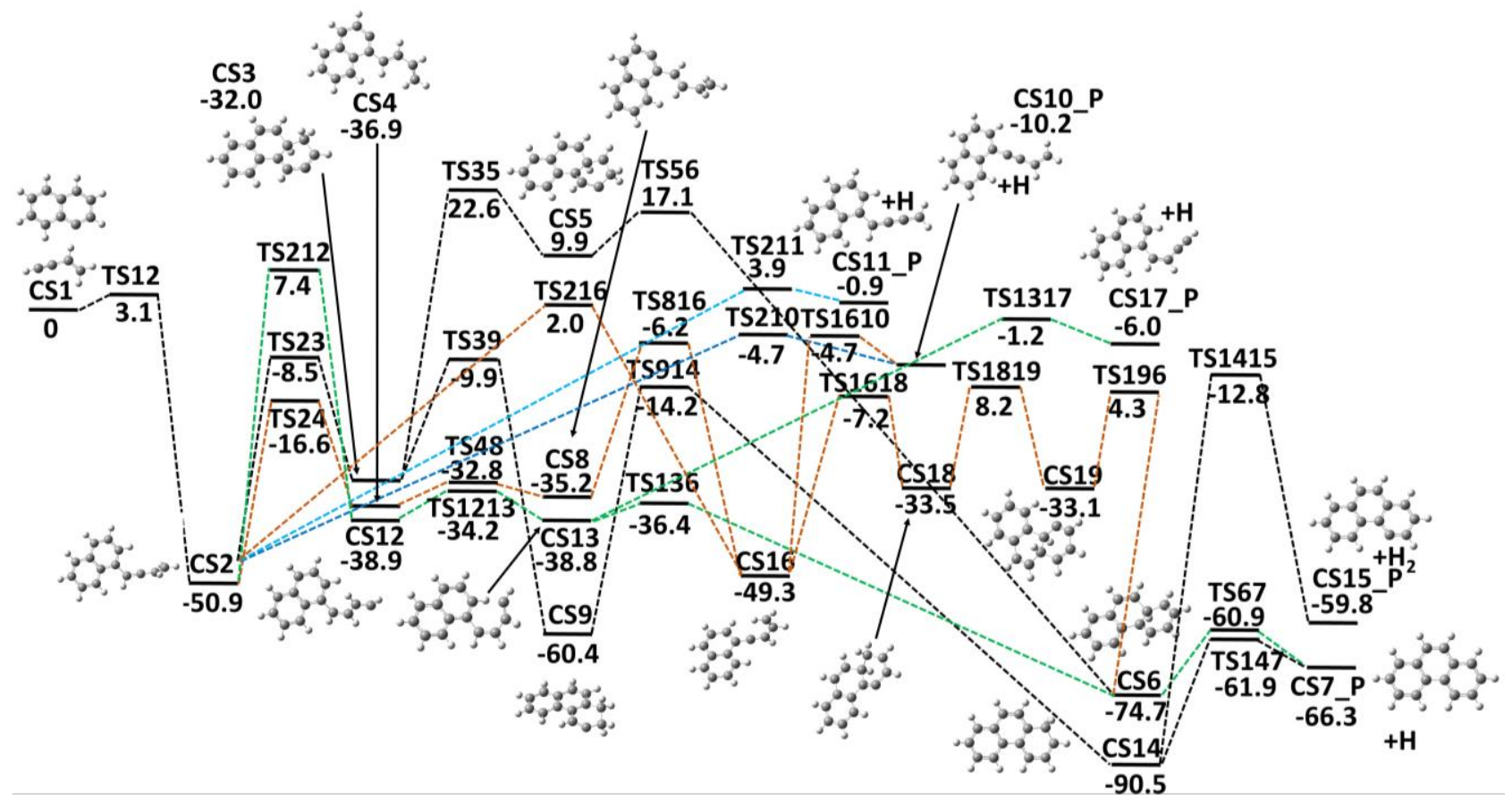

Fig. 2 Potential energy surface of reaction $\mathrm{A}_{2}-1+\mathrm{C}_{4} \mathrm{H}_{4}(\mathrm{C} 1)$, energies calculated at CBS-QB3 level. 


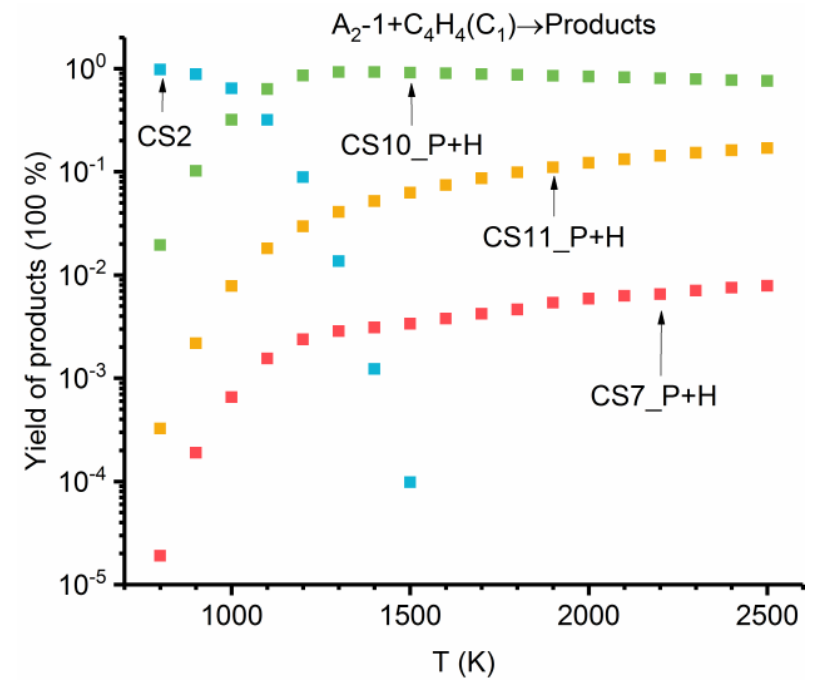

(a)

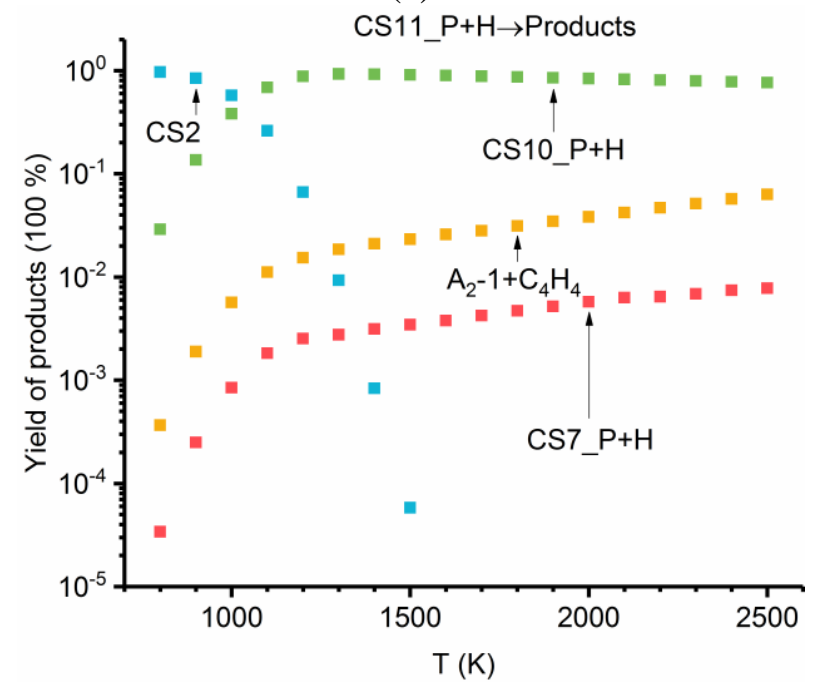

(c)

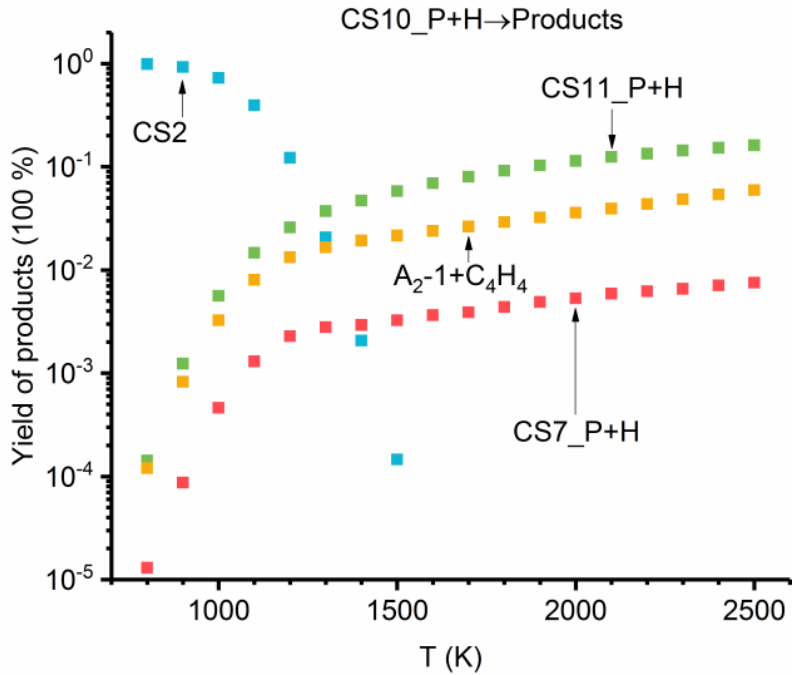

(b)

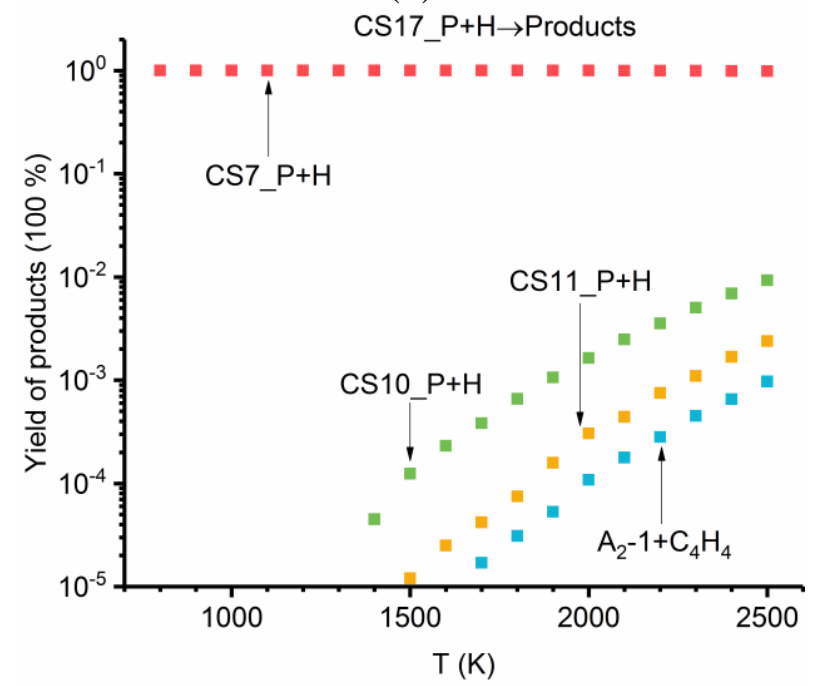

(d)

Fig. 3 Yield distribution of products in $\mathrm{A}_{2}-1+\mathrm{C}_{4} \mathrm{H}_{4}(\mathrm{C} 1)$ reaction system at $1 \mathrm{~atm}$. 


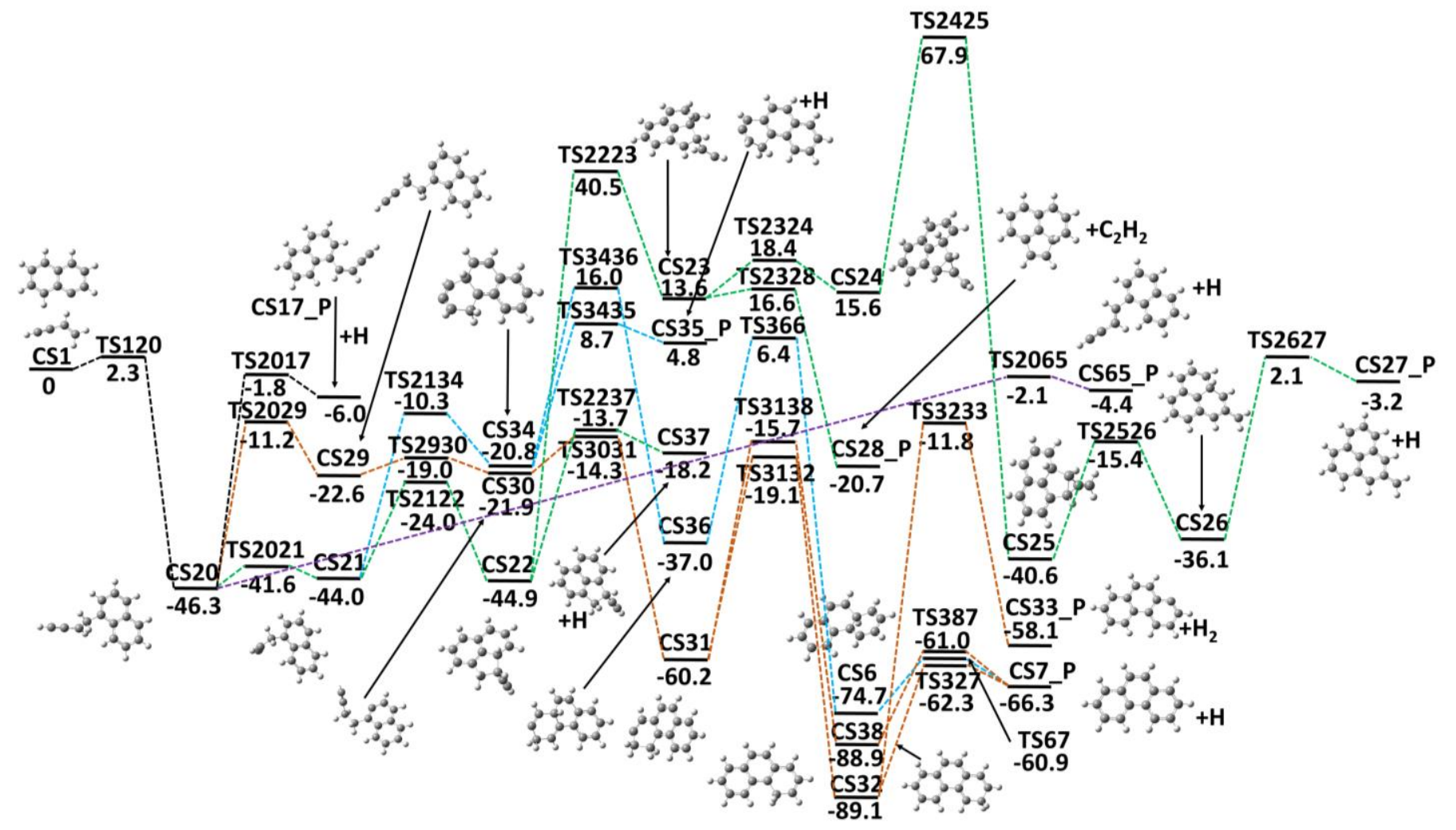

Fig. 4 Potential energy surface of reaction $\mathrm{A}_{2}-1+\mathrm{C}_{4} \mathrm{H}_{4}(\mathrm{C} 4)$, energies calculated at CBS-QB3 level.

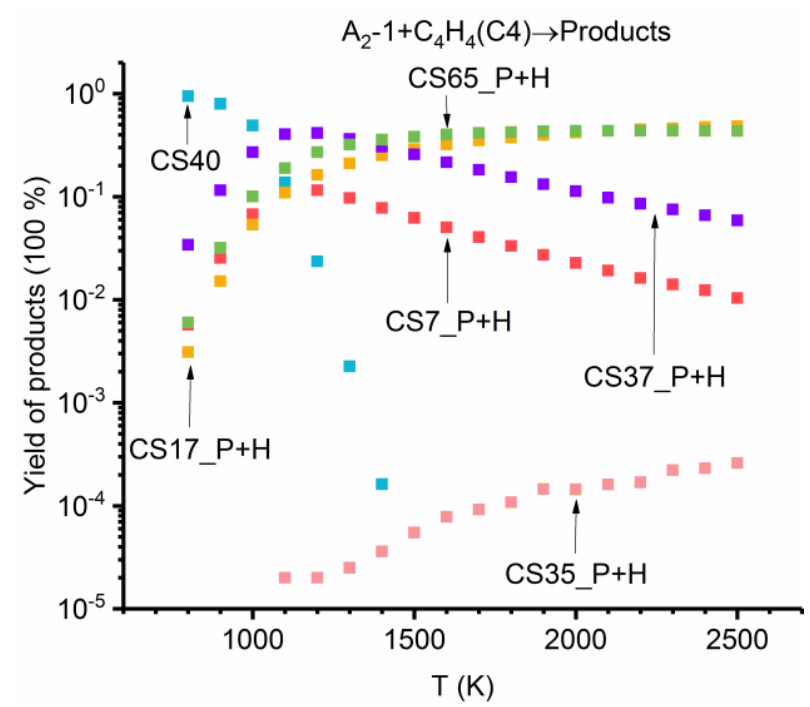

(a)

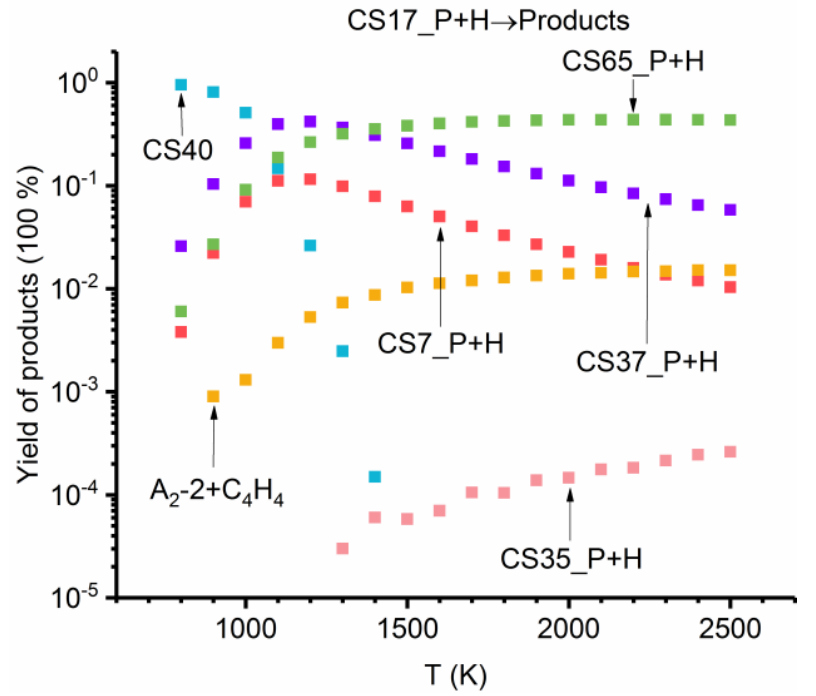

(b) 


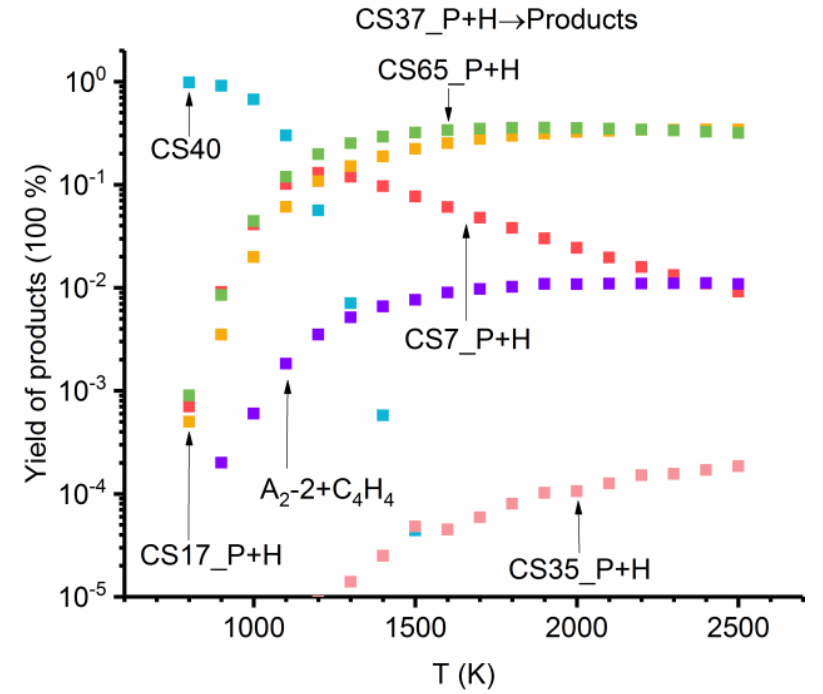

(c)

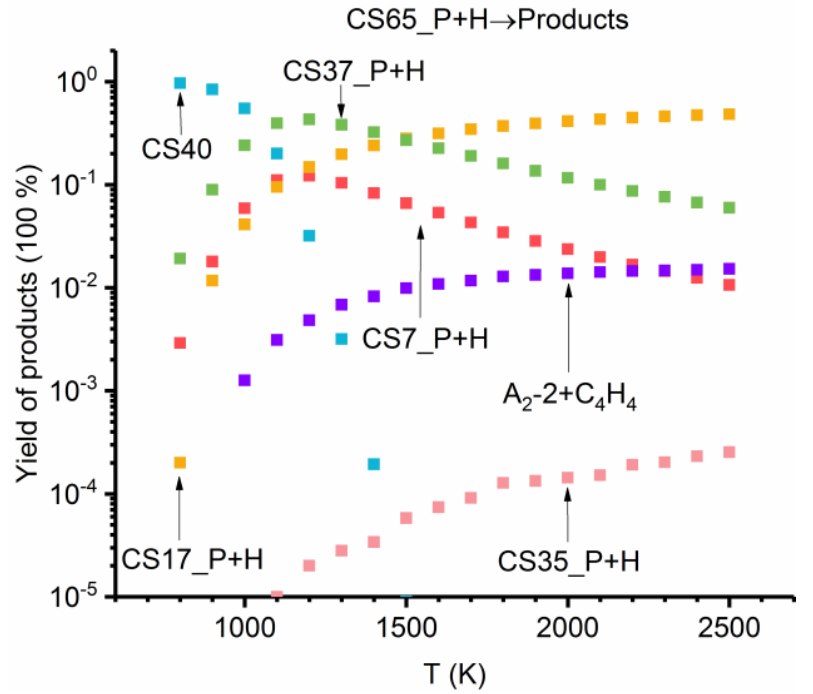

(d)

Fig.5 Yield distribution of products in $\mathrm{A}_{2}-1+\mathrm{C}_{4} \mathrm{H}_{4}(\mathrm{C} 4)$ reaction system at $1 \mathrm{~atm}$.

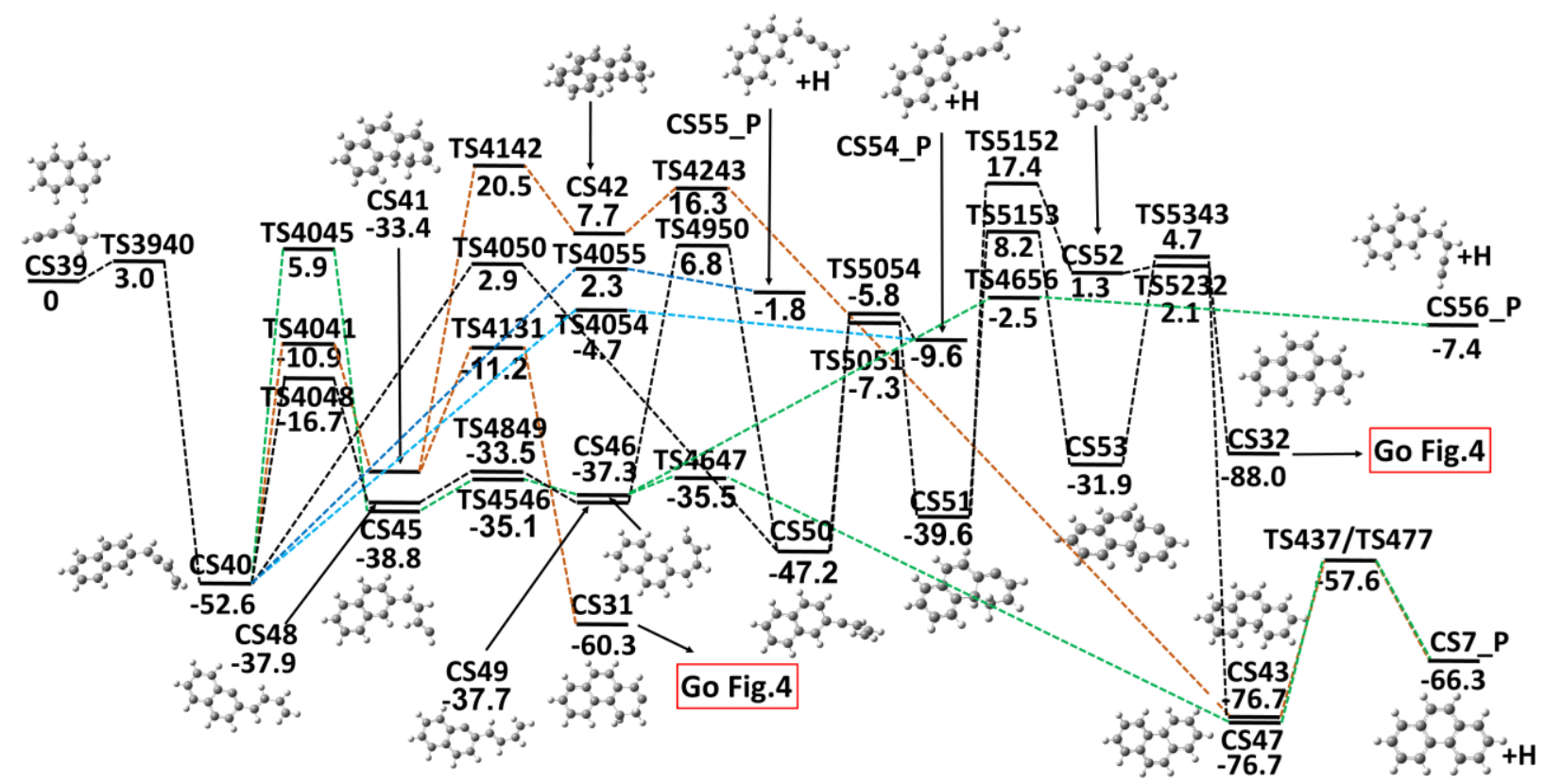

Fig. 6 Potential energy surface of reaction $\mathrm{A}_{2}-2$ and $\mathrm{C}_{4} \mathrm{H}_{4}\left(\mathrm{C}_{1}\right)$, energies calculated at CBS-QB3 level. 


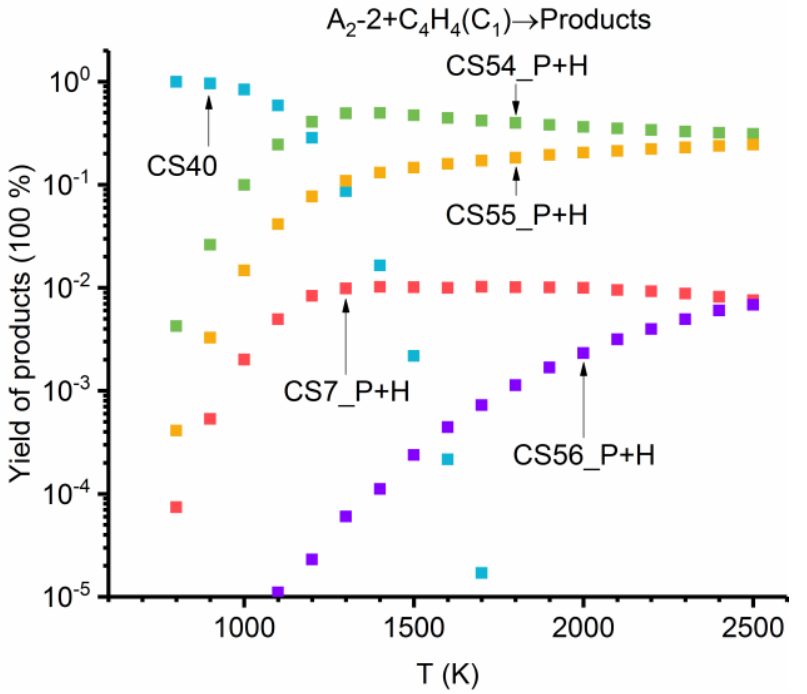

(a)

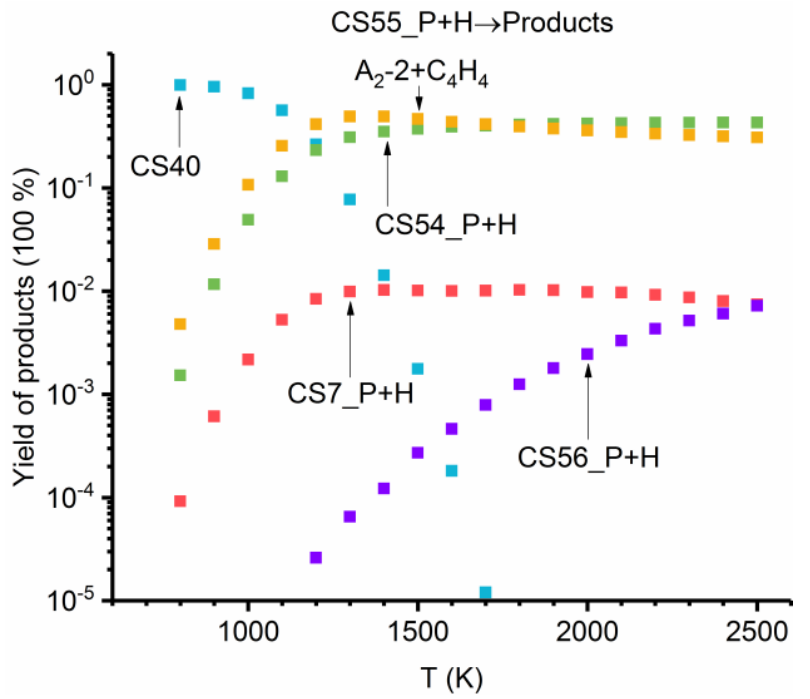

(c)

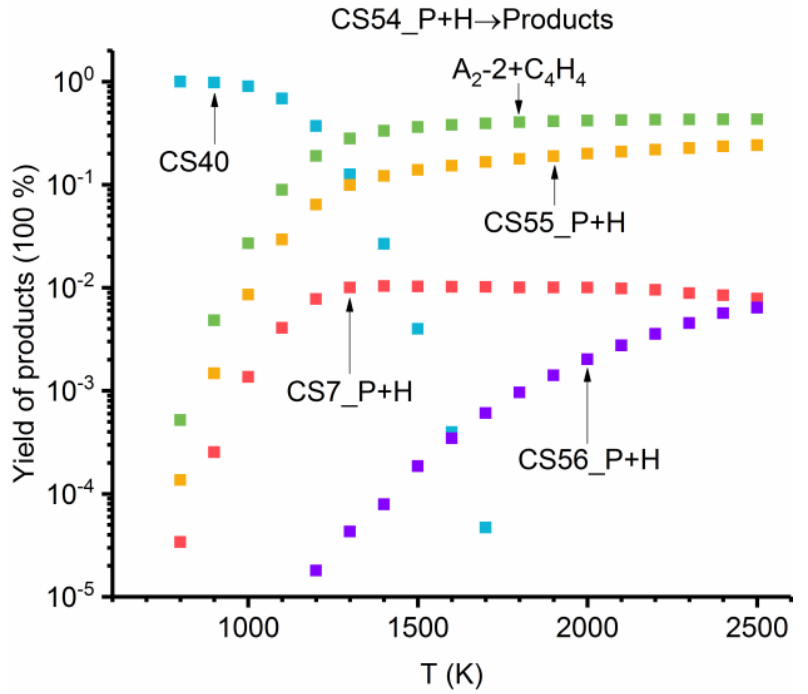

(b)

CS56_P $+\mathrm{H} \rightarrow$ Products

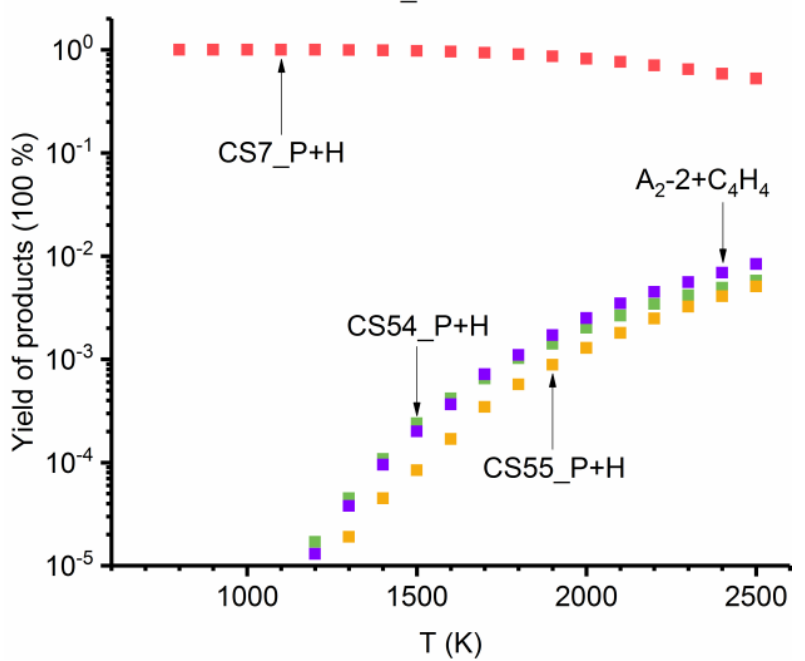

(d)

Fig. 7 Yield of products in $\mathrm{A}_{2}-2+\mathrm{C}_{4} \mathrm{H}_{4}(\mathrm{C} 1)$ reaction system.

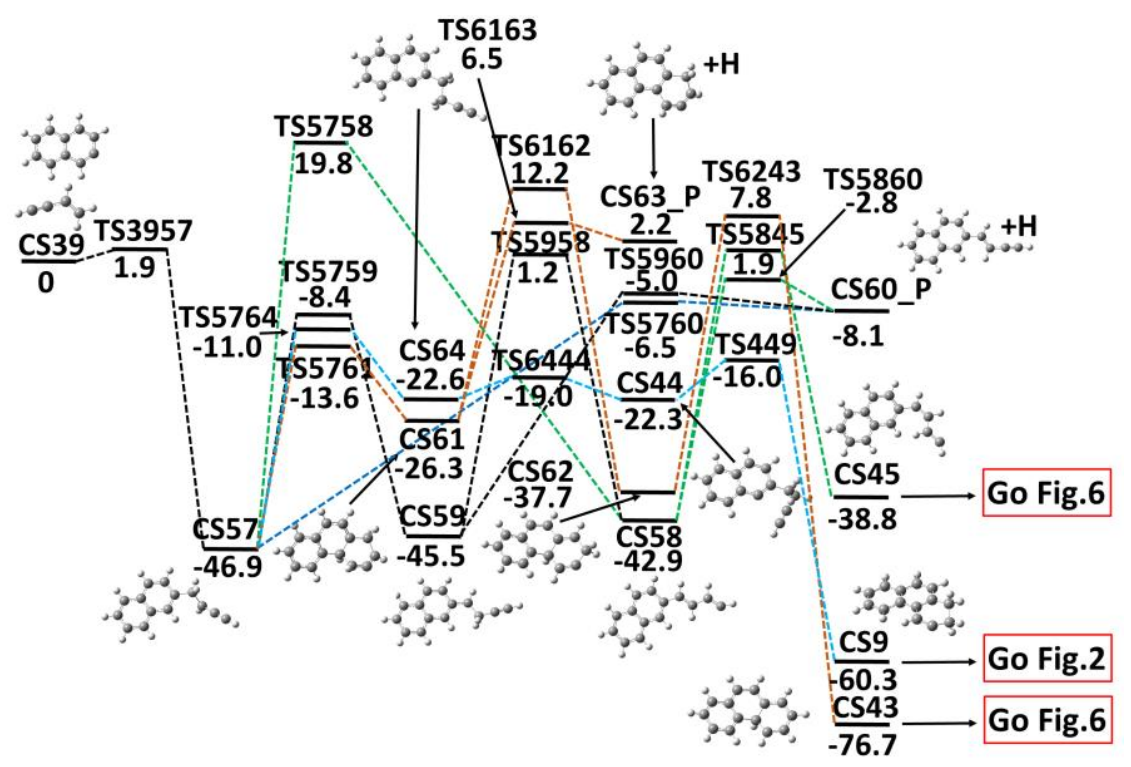


Fig. 8 Potential energy surface of reaction $\mathrm{A}_{2}-2$ and $\mathrm{C}_{4} \mathrm{H}_{4}\left(\mathrm{C}_{4}\right)$, energies calculated at CBS-QB3 level.

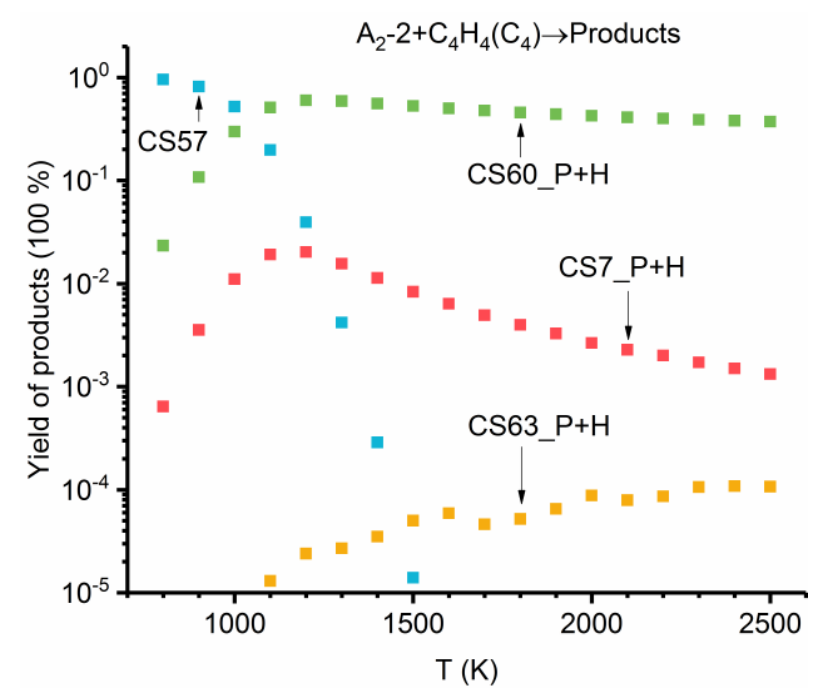

(a)

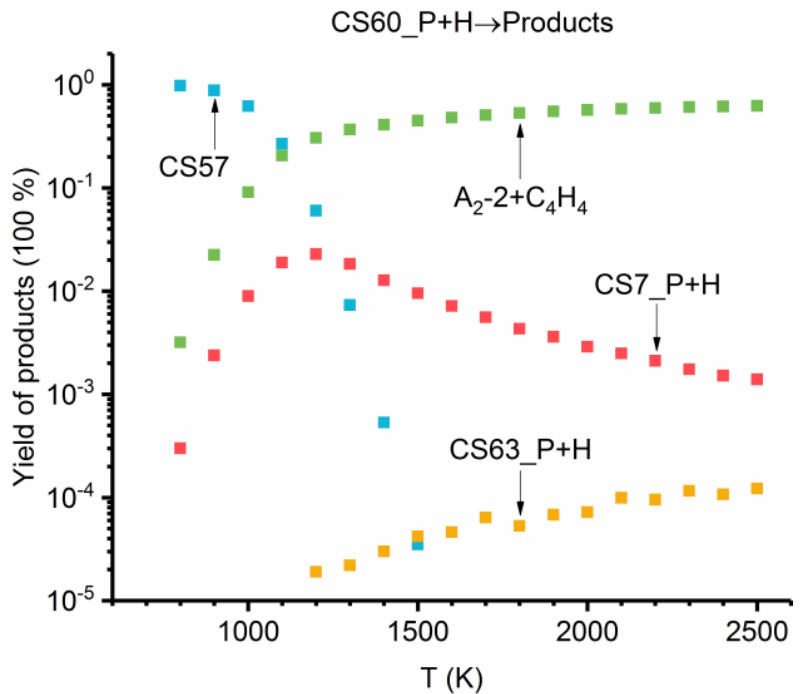

(b)

Fig. 9 Yield distribution of products in the reaction of $\mathrm{A}_{2}-2$ and $\mathrm{C}_{4} \mathrm{H}_{4}\left(\mathrm{C}_{4}\right)$.

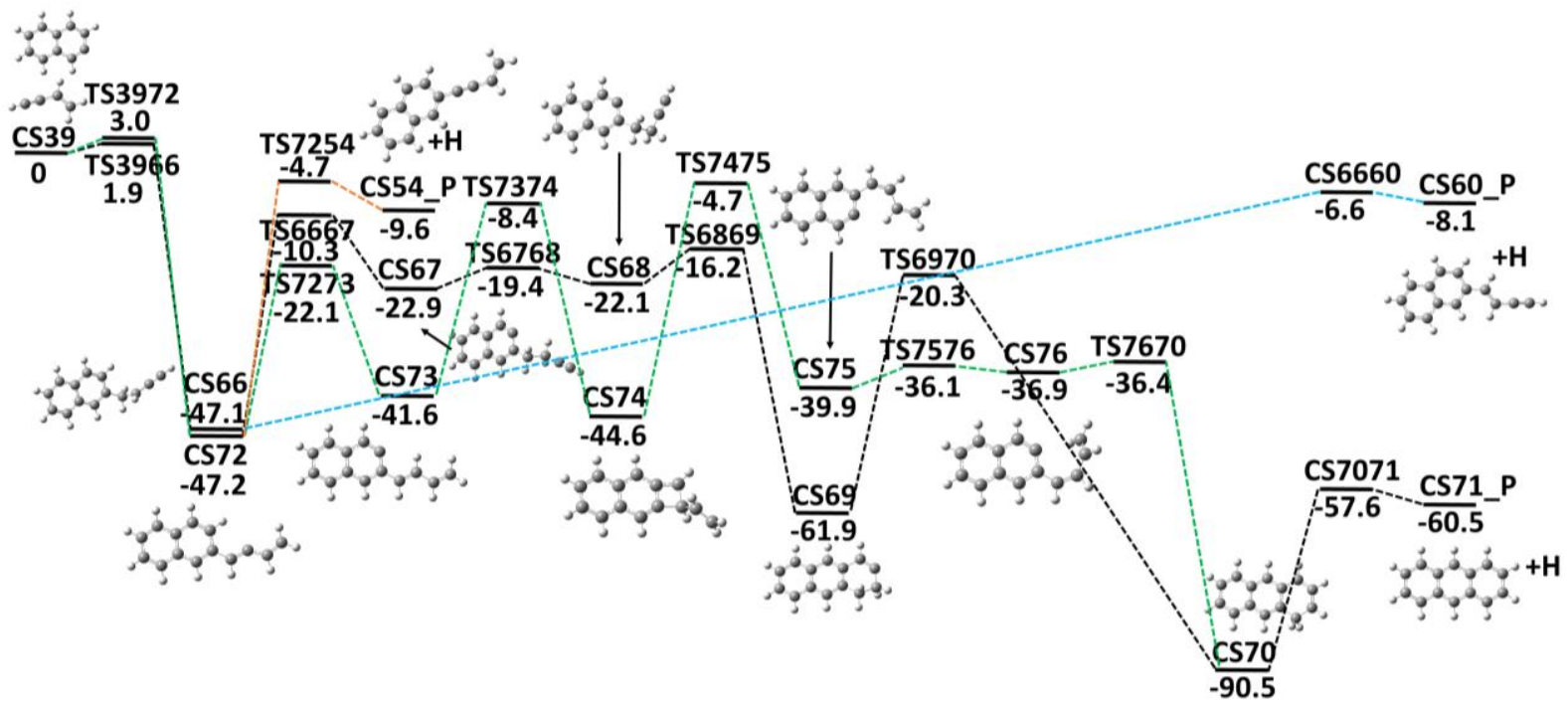

Fig. 10 Potential energy surface for anthracene formation in reaction $\mathrm{A}_{2}-2+\mathrm{C}_{4} \mathrm{H}_{4}$, energies calculated at CBSQB3 level. 


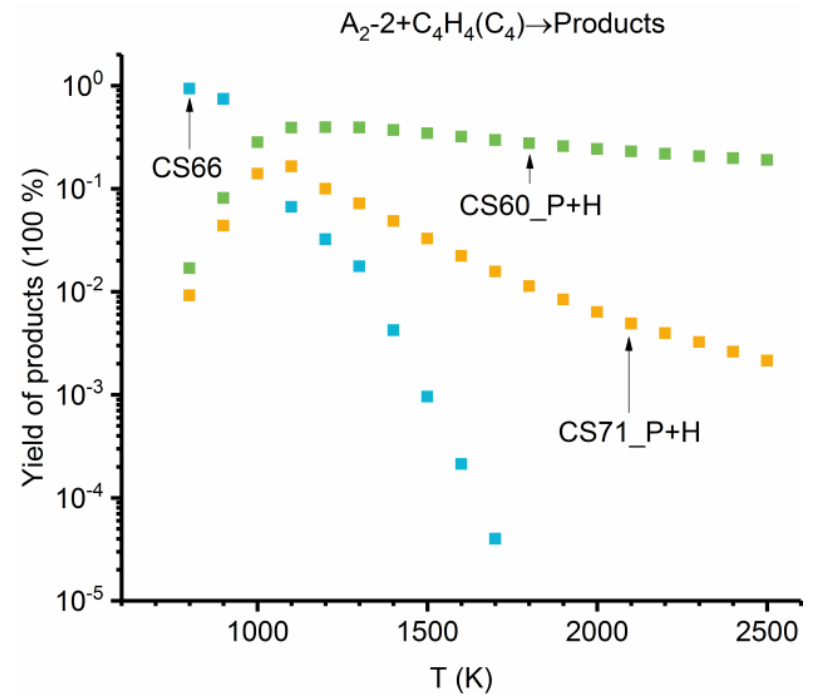

(a)

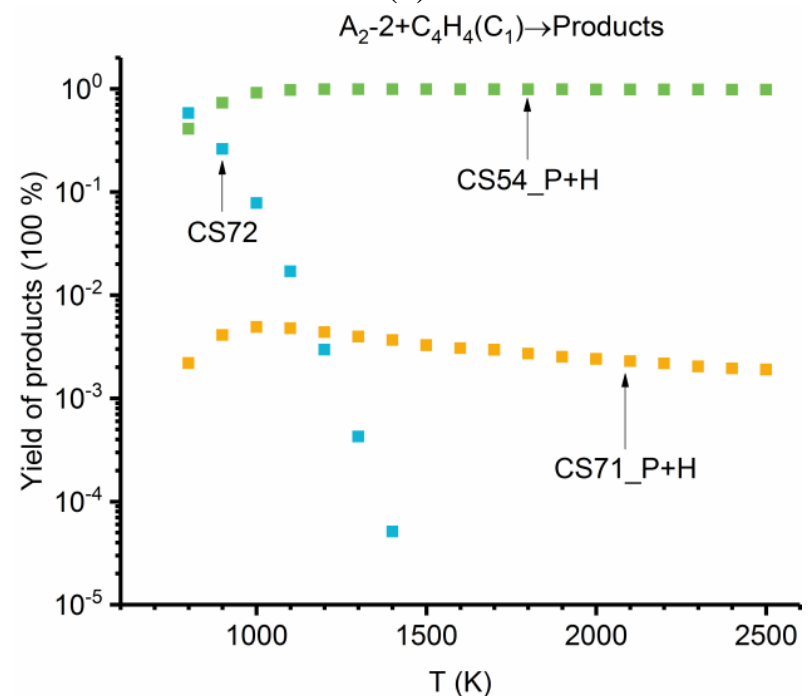

(c)

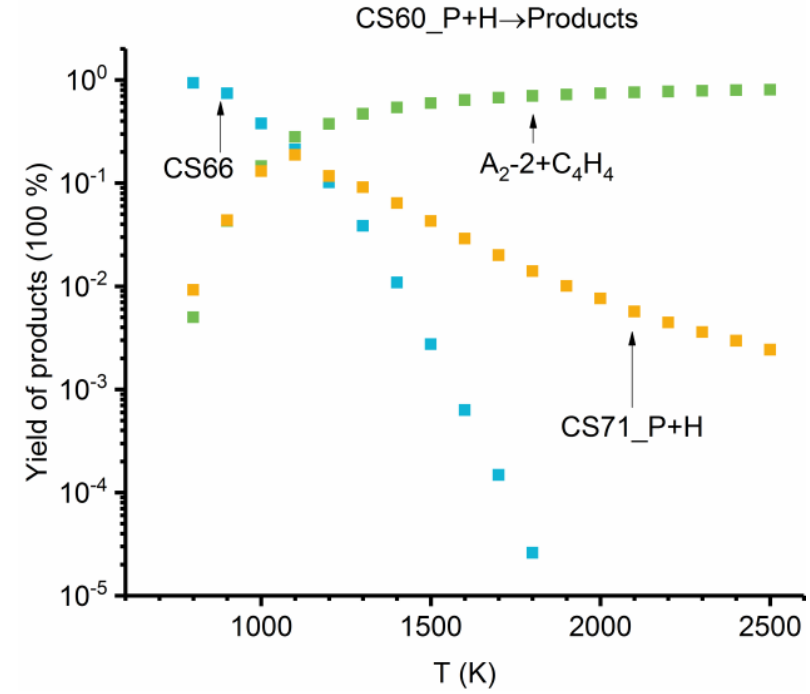

(b)

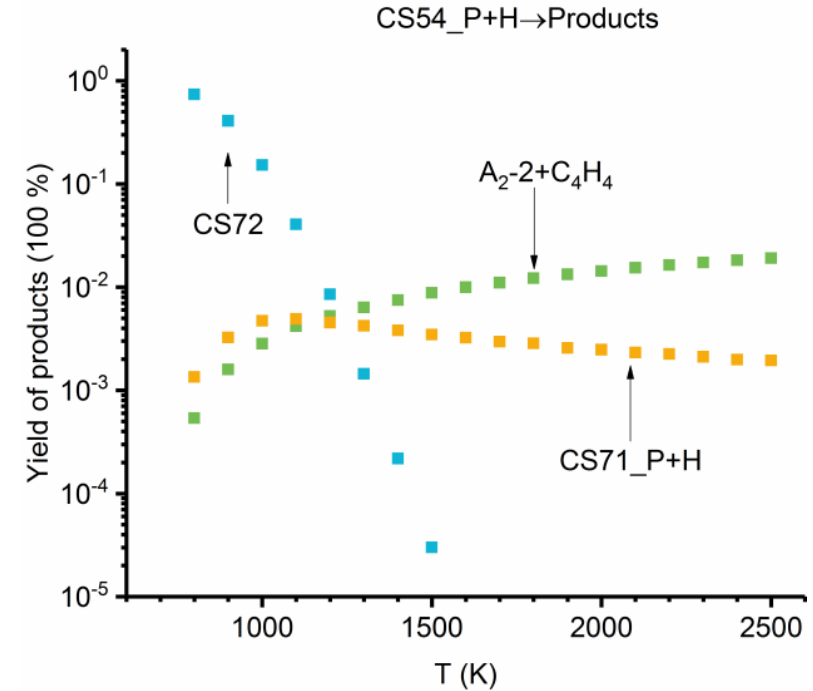

(d)

Fig. 11 Yield distribution of products in anthracene formation reaction system $\left(\mathrm{A}_{2}-2+\mathrm{C}_{4} \mathrm{H}_{4}\right)$.

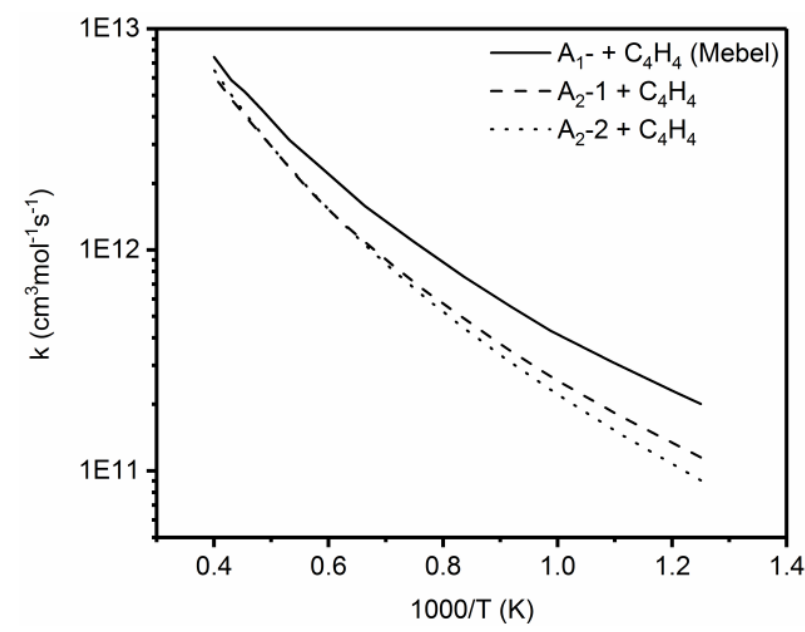

(a)

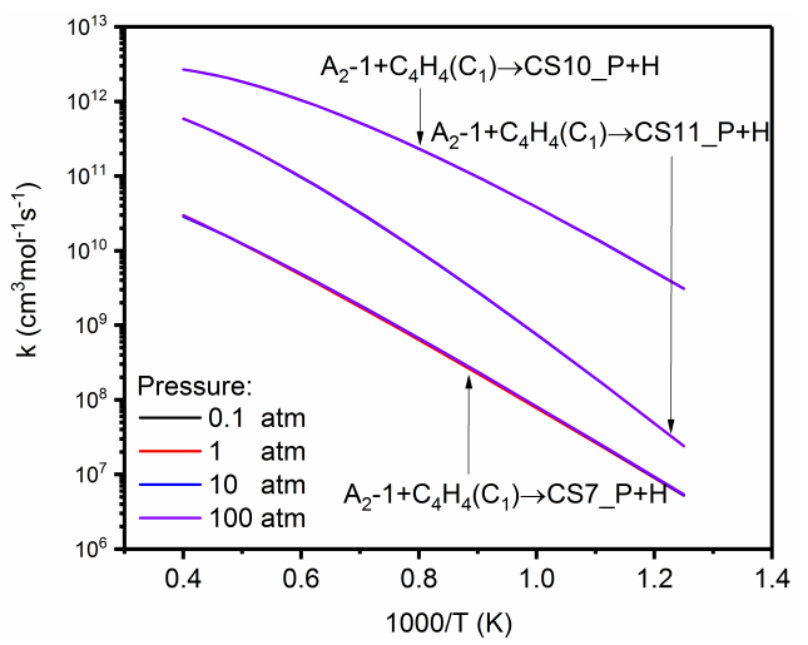

(b) 
Fig. 12 Calculated rate coefficients. (a) total addition reaction rate at high-pressure limit, (b) rate coefficients for formation of individual products in $\mathrm{A}_{2}-1+\mathrm{C}_{4} \mathrm{H}_{4}$ reaction at pressure of $0.1,1,10$, and 100 atm, respectively.

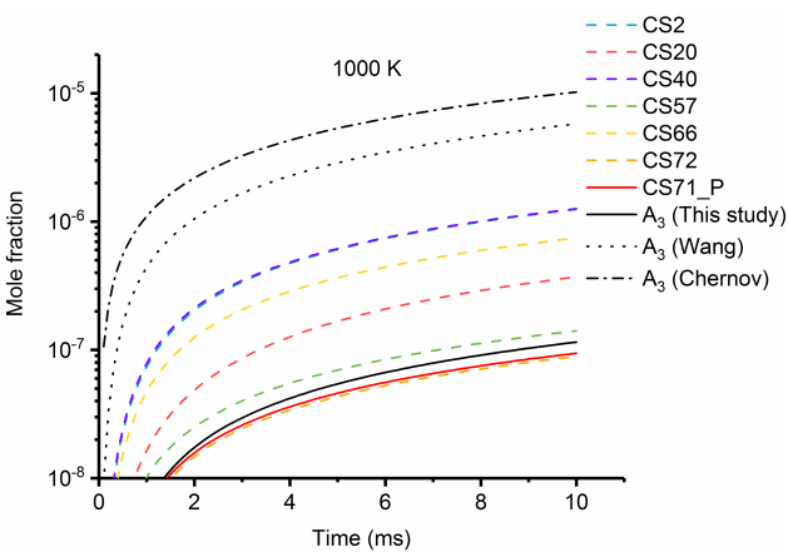

(a)

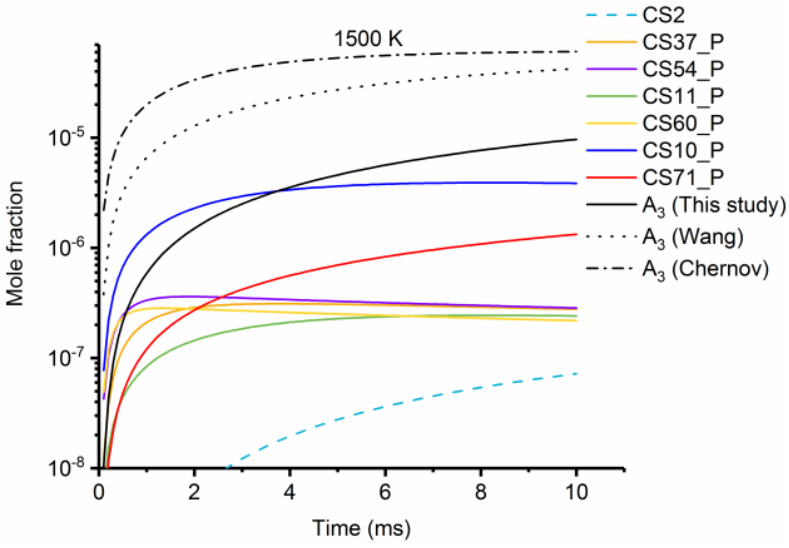

(c)

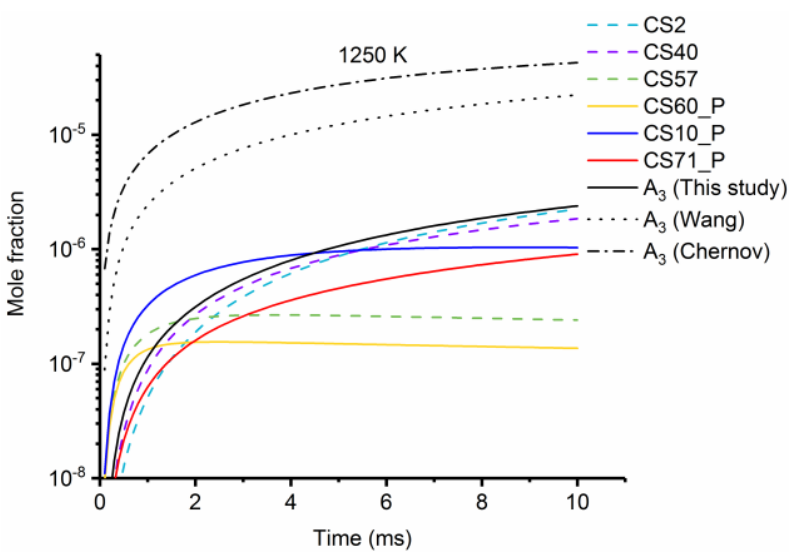

(b)

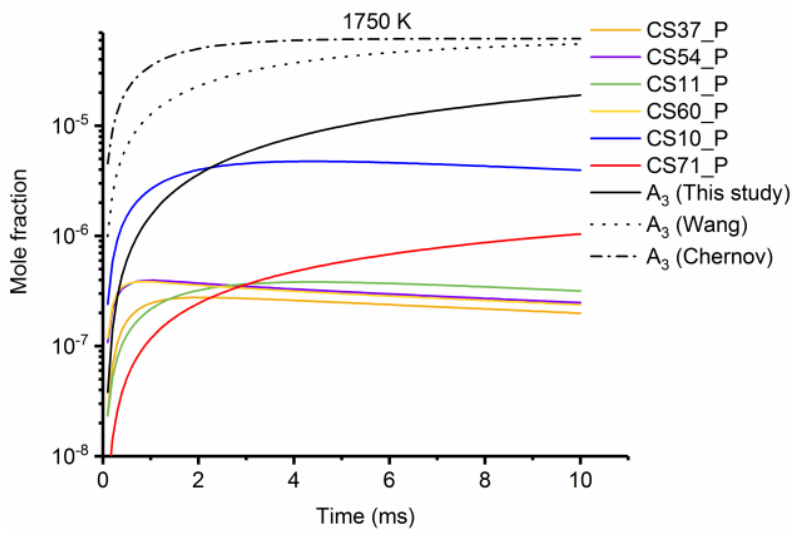

(d)

Fig. 13 Yield distribution of products for $\mathrm{A}_{2}-\mathrm{H}-\mathrm{C}_{4} \mathrm{H}_{4}$ reaction system in a 0-D reactor.

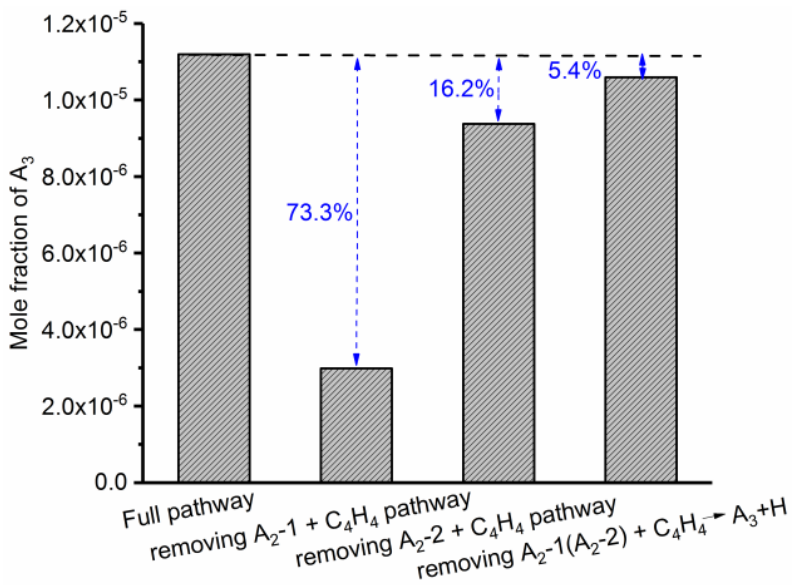

Fig.14 Sensitivity analysis of $\mathrm{A}_{3}$ formation at zig-zag and free edge surface sites. 


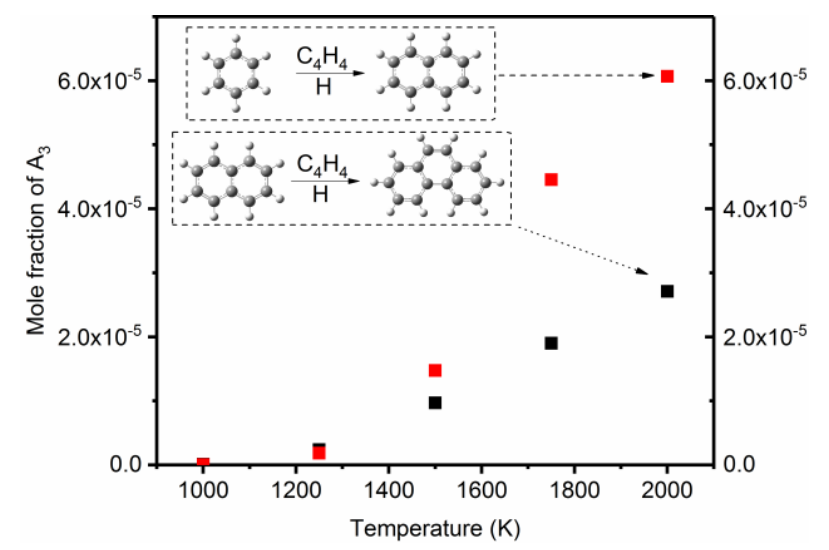

Fig.15 Formation of new benzene ring in $\mathrm{A}_{1}-\mathrm{H}-\mathrm{C}_{4} \mathrm{H}_{4}\left(\mathrm{~A}_{2}\right)$ and $\mathrm{A}_{2}-\mathrm{H}-\mathrm{C}_{4} \mathrm{H}_{4}\left(\mathrm{~A}_{3}\right)$ reaction systems, reaction time = $10 \mathrm{~ms}$.

Table 1. Reaction rate parameters for $\mathrm{A}_{1}-\mathrm{H}-\mathrm{C}_{4} \mathrm{H}_{4}$ system, in the form of $\mathrm{AT}^{\mathrm{n}} \exp (-\mathrm{E} / \mathrm{RT})$, units are s${ }^{-1}, \mathrm{~cm}^{3} \mathrm{~mol}^{-}$ ${ }^{1} \mathrm{~S}^{-1}$ and kcal.

\begin{tabular}{ccccc}
\hline Reaction & $\mathrm{A}$ & $\mathrm{n}$ & $\mathrm{E}$ & Reference \\
\hline $\mathrm{A}_{1}+\mathrm{H} \rightarrow \mathrm{A}_{1}-+\mathrm{H}_{2}$ & $6.75 \times 10^{8}$ & 1.910 & 15.61 & {$[16]$} \\
$\mathrm{A}_{1}-+\mathrm{H}_{2} \rightarrow \mathrm{A}_{1}+\mathrm{H}$ & $1.22 \times 10^{4}$ & 2.655 & 42.66 & {$[16]$} \\
$\mathrm{A}_{1}-\mathrm{C}_{4} \mathrm{H}_{4} \rightarrow \mathrm{P} 3+\mathrm{H}$ & $3.80 \times 10^{-10}$ & 6.780 & 14.68 & {$[25]$} \\
$\mathrm{P} 3+\mathrm{H} \rightarrow \mathrm{A}_{1}-+\mathrm{C}_{4} \mathrm{H}_{4}$ & $2.32 \times 10^{-1}$ & 4.840 & 23.21 & {$[25]$} \\
$\mathrm{P} 3+\mathrm{H} \rightarrow \mathrm{P} 2+\mathrm{H}$ & $2.84 \times 10^{16}$ & 0.120 & 27.31 & {$[25]$} \\
$\mathrm{P} 2+\mathrm{H} \rightarrow \mathrm{P} 3+\mathrm{H}$ & $3.13 \times 10^{16}$ & 0.150 & 26.58 & {$[25]$} \\
$\mathrm{P} 2+\mathrm{H} \rightarrow \mathrm{A}_{2}+\mathrm{H}$ & $1.50 \times 10^{18}$ & -0.950 & 15.43 & {$[25]$} \\
$\mathrm{P} 3+\mathrm{H} \rightarrow \mathrm{A}_{2}+\mathrm{H}$ & $8.49 \times 10^{31}$ & -4.660 & 29.38 & {$[25]$} \\
\hline
\end{tabular}

P2 and P3 represent cis-1-phenyl-vinylacetylene and trans-1-phenyl-vinylacetylene, respectively.

Table 2. Reaction rate parameters in the form of $\mathrm{AT}^{\mathrm{n}} \exp (-\mathrm{E} / \mathrm{RT})$, units are $\mathrm{s}^{-1}, \mathrm{~cm}^{3} \mathrm{~mol}^{-1} \mathrm{~s}^{-1}$ and Kcal.

\begin{tabular}{|c|c|c|c|c|c|c|}
\hline Reaction & $\begin{array}{c}\text { Entrance } \\
\text { well }\end{array}$ & $\bar{A}$ & $\bar{n}$ & $\bar{E}$ & Valid $\mathrm{T}$ range $(\mathrm{K})$ & $\mathrm{P}$ (atm) \\
\hline $\mathrm{A}_{2}-1+\mathrm{C}_{4} \mathrm{H}_{4} \rightarrow \mathrm{CS} 2$ & $\mathrm{CS} 2$ & $2.59 \times 10^{289}$ & -81.54 & 155.02 & $800-1600$ & $0.1-100$ \\
\hline $\mathrm{A}_{2}-1+\mathrm{C}_{4} \mathrm{H}_{4} \rightarrow \mathrm{A}_{3}+\mathrm{H}$ & $\mathrm{CS} 2$ & $9.52 \times 10^{18}$ & -1.862 & 25.08 & $800-2500$ & $0.1-100$ \\
\hline${ }^{*} \mathrm{~A}_{2}-1+\mathrm{C}_{4} \mathrm{H}_{4} \rightarrow \mathrm{CS} 10 \_\mathrm{P}+\mathrm{H}$ & $\mathrm{CS} 2$ & $7.05 \times 10^{30}$ & -4.693 & 28.68 & $800-2500$ & $0.1-100$ \\
\hline $\mathrm{A}_{2}-1+\mathrm{C}_{4} \mathrm{H}_{4} \rightarrow \mathrm{CS} 11 \_\mathrm{P}+\mathrm{H}$ & $\mathrm{CS} 2$ & $2.17 \times 10^{29}$ & -4.271 & 34.96 & $800-2500$ & $0.1-100$ \\
\hline $\mathrm{CS} 10 \_\mathrm{P}+\mathrm{H} \rightarrow \mathrm{CS} 2$ & $\mathrm{CS} 2+\mathrm{CS} 16$ & $3.13 \times 10^{293}$ & -82.31 & 155.32 & $800-1600$ & $0.1-100$ \\
\hline${ }^{*} \mathrm{CS} 10 \_\mathrm{P}+\mathrm{H} \rightarrow \mathrm{CS} 7 \_\mathrm{P}+\mathrm{H}$ & $\mathrm{CS} 2+\mathrm{CS} 16$ & $2.19 \times 10^{34}$ & -5.869 & 33.62 & $800-2500$ & $0.1-100$ \\
\hline $\mathrm{CS} 10 \_\mathrm{P}+\mathrm{H} \rightarrow \mathrm{CS} 11 \_\mathrm{P}+\mathrm{H}$ & $\mathrm{CS} 2+\mathrm{CS} 16$ & $1.94 \times 10^{42}$ & -7.615 & 41.50 & $800-2500$ & $0.1-100$ \\
\hline${ }^{*} \mathrm{CS} 10 \_\mathrm{P}+\mathrm{H} \rightarrow \mathrm{A}_{2}-1+\mathrm{C}_{4} \mathrm{H}_{4}$ & $\mathrm{CS} 2+\mathrm{CS} 16$ & $2.51 \times 10^{27}$ & -3.723 & 27.30 & $800-2500$ & $0.1-100$ \\
\hline $\mathrm{CS} 11 \_\mathrm{P}+\mathrm{H} \rightarrow \mathrm{CS} 2$ & $\mathrm{CS} 2$ & $6.82 \times 10^{302}$ & -85.12 & 160.92 & $800-1500$ & $0.1-100$ \\
\hline $\mathrm{CS} 11 \_\mathrm{P}+\mathrm{H} \rightarrow \mathrm{A}_{3}+\mathrm{H}$ & $\mathrm{CS} 2$ & $1.06 \times 10^{21}$ & -2.094 & 24.08 & $800-2500$ & $0.1-100$ \\
\hline $\mathrm{CS} 11$-P+H $\rightarrow$ CS10_P+H & $\mathrm{CS} 2$ & $4.40 \times 10^{30}$ & -4.298 & 25.62 & $800-2500$ & $0.1-100$ \\
\hline $\mathrm{CS} 11{ }_{-}^{-} \mathrm{P}+\mathrm{H} \rightarrow \mathrm{A}_{2}-1+\mathrm{C}_{4} \mathrm{H}_{4}$ & $\mathrm{CS} 2$ & $3.19 \times 10^{27}$ & -3.616 & 29.56 & $800-2500$ & $0.1-100$ \\
\hline${ }^{*} \mathrm{CS} 17 \_\mathrm{P}+\mathrm{H} \rightarrow \mathrm{CS} 7 \_\mathrm{P}+\mathrm{H}$ & CS20+CS13 & $1.44 \times 10^{9}$ & 1.530 & 5.16 & $800-2500$ & $0.1-100$ \\
\hline${ }^{*} \mathrm{CS} 17 \_\mathrm{P}+\mathrm{H} \rightarrow \mathrm{CS} 10 \_\mathrm{P}+\mathrm{H}$ & CS13 & $9.92 \times 10^{6}$ & 2.338 & 35.12 & $1400-2500$ & $0.1-100$ \\
\hline $\mathrm{CS} 17 \_\mathrm{P}+\mathrm{H} \rightarrow \mathrm{CS} 11 \_\mathrm{P}+\mathrm{H}$ & CS13 & $4.85 \times 10^{8}$ & 1.838 & 42.64 & $1400-2500$ & $0.1-100$ \\
\hline $\mathrm{A}_{2}-1+\mathrm{C}_{4} \mathrm{H}_{4} \rightarrow \mathrm{CS} 2 \overline{0}$ & $\mathrm{CS} 20$ & $3.77 \times 10^{260}$ & -74.06 & 128.74 & $800-1500$ & $0.1-100$ \\
\hline
\end{tabular}




\begin{tabular}{|c|c|c|c|c|c|c|}
\hline $\mathrm{A}_{2}-1+\mathrm{C}_{4} \mathrm{H}_{4} \rightarrow \mathrm{CS} 7 \_\mathrm{P}+\mathrm{H}$ & CS20 & $2.14 \times 10^{53}$ & -11.73 & 39.84 & $800-2500$ & $0.1-100$ \\
\hline $\mathrm{A}_{2}-1+\mathrm{C}_{4} \mathrm{H}_{4} \rightarrow \mathrm{CS} 35 \_\mathrm{P}+\mathrm{H}$ & CS20 & $2.60 \times 10^{10}$ & 0 & 21.90 & $800-2500$ & $0.1-100$ \\
\hline${ }^{*} \mathrm{~A}_{2}-1+\mathrm{C}_{4} \mathrm{H}_{4} \rightarrow \mathrm{CS} 17 \_\mathrm{P}+\mathrm{H}$ & CS20 & $4.47 \times 10^{32}$ & -5.286 & 33.82 & $800-2500$ & $0.1-100$ \\
\hline${ }^{*} \mathrm{~A}_{2}-1+\mathrm{C}_{4} \mathrm{H}_{4} \rightarrow \mathrm{CS} 37 \_\mathrm{P}+\mathrm{H}$ & CS20 & $4.55 \times 10^{37}$ & -7.207 & 26.74 & $800-2500$ & $0.1-100$ \\
\hline${ }^{*} \mathrm{~A}_{2}-1+\mathrm{C}_{4} \mathrm{H}_{4} \rightarrow \mathrm{CS} 65 \_\mathrm{P}+\mathrm{H}$ & CS20 & $1.80 \times 10^{36}$ & -6.346 & 34.58 & $800-2500$ & $0.1-100$ \\
\hline $\mathrm{CS} 17 \_\mathrm{P}+\mathrm{H} \rightarrow \mathrm{CS} 20$ & CS20 & $7.01 \times 10^{291}$ & -82.52 & 149.78 & $800-1500$ & $0.1-100$ \\
\hline $\mathrm{CS} 17 \_\mathrm{P}+\mathrm{H} \rightarrow \mathrm{CS} 35 \_\mathrm{P}+\mathrm{H}$ & CS20 & $6.26 \times 10^{6}$ & 1.304 & 16.85 & $800-2500$ & $0.1-100$ \\
\hline${ }^{*} \mathrm{CS} 17 \_\mathrm{P}+\mathrm{H} \rightarrow \mathrm{A}_{2}-1+\mathrm{C}_{4} \mathrm{H}_{4}$ & $\mathrm{CS} 20+\mathrm{CS} 13$ & $1.28 \times 10^{28}$ & -4.135 & 29.42 & $800-2500$ & $0.1-100$ \\
\hline${ }^{*} \mathrm{CS} 17 \_\mathrm{P}+\mathrm{H} \rightarrow \mathrm{CS} 37 \_\mathrm{P}+\mathrm{H}$ & CS20 & $1.47 \times 10^{45}$ & -8.934 & 31.82 & $800-2500$ & $0.1-100$ \\
\hline${ }^{*} \mathrm{CS} 17 \_\mathrm{P}+\mathrm{H} \rightarrow \mathrm{CS} 65 \_\mathrm{P}+\mathrm{H}$ & CS20 & $2.67 \times 10^{42}$ & -7.709 & 38.62 & $800-2500$ & $0.1-100$ \\
\hline $\mathrm{CS} 3 \overline{7} \_\mathrm{P}+\mathrm{H} \rightarrow \mathrm{CS} 20$ & CS20 & $3.68 \times 10^{270}$ & -76.38 & 136.22 & $800-1600$ & $0.1-100$ \\
\hline${ }^{*} \mathrm{CS} 37 \_\mathrm{P}+\mathrm{H} \rightarrow \mathrm{CS} 7 \_\mathrm{P}+\mathrm{H}$ & CS20 & $9.22 \times 10^{69}$ & -16.10 & 51.00 & $800-2500$ & $0.1-100$ \\
\hline $\mathrm{CS} 37 \_\mathrm{P}+\mathrm{H} \rightarrow \mathrm{CS} 35 \_\mathrm{P}+\mathrm{H}$ & CS20 & $9.86 \times 10^{20}$ & -2.646 & 31.10 & $1200-2500$ & $0.1-100$ \\
\hline${ }^{*} \mathrm{CS} 37 \_\mathrm{P}+\mathrm{H} \rightarrow \mathrm{CS} 17 \_\mathrm{P}+\mathrm{H}$ & CS20 & $4.33 \times 10^{52}$ & -10.57 & 49.38 & $1200-2500$ & $0.1-100$ \\
\hline${ }^{*} \mathrm{CS} 37 \_\mathrm{P}+\mathrm{H} \rightarrow \mathrm{A}_{2}-1+\mathrm{C}_{4} \mathrm{H}_{4}$ & CS20 & $4.62 \times 10^{42}$ & -8.26 & 41.50 & $900-2500$ & $0.1-100$ \\
\hline${ }^{*} \mathrm{CS} 37 \_\mathrm{P}+\mathrm{H} \rightarrow \mathrm{CS} 65 \_\mathrm{P}+\mathrm{H}$ & CS20 & $9.51 \times 10^{57}$ & -12.10 & 51.42 & $800-2500$ & $0.1-100$ \\
\hline $\mathrm{CS} 65$ 5 $+\mathrm{H} \rightarrow \mathrm{CS} 20$ & CS20 & $2.26 \times 10^{265}$ & -74.93 & 127.9 & $800-1500$ & $0.1-100$ \\
\hline${ }^{*} \mathrm{CS} 65 \_\overline{\mathrm{P}}+\mathrm{H} \rightarrow \mathrm{CS} 7 \_\mathrm{P}+\mathrm{H}$ & CS20 & $2.12 \times 10^{57}$ & -12.48 & 37.02 & $800-2500$ & $0.1-100$ \\
\hline $\mathrm{CS} 65 \_\mathrm{P}+\mathrm{H} \rightarrow \mathrm{CS} 35 \_\mathrm{P}+\mathrm{H}$ & CS20 & $5.95 \times 10^{14}$ & -0.8253 & 20.44 & $800-2500$ & $0.1-100$ \\
\hline${ }^{*} \mathrm{CS} 65 \_\mathrm{P}+\mathrm{H} \rightarrow \mathrm{CS} 17 \_\mathrm{P}+\mathrm{H}$ & CS20 & $3.10 \times 10^{34}$ & -5.438 & 29.72 & $800-2500$ & $0.1-100$ \\
\hline${ }^{*} \mathrm{CS} 65 \_\mathrm{P}+\mathrm{H} \rightarrow \mathrm{A}_{2}-1+\mathrm{C}_{4} \mathrm{H}_{4}$ & CS20 & $5.94 \times 10^{30}$ & -4.848 & 27.14 & $800-2500$ & $0.1-100$ \\
\hline${ }^{*} \mathrm{CS} 65 \_\mathrm{P}+\mathrm{H} \rightarrow \mathrm{CS} 37 \_\mathrm{P}+\mathrm{H}$ & CS20 & $8.83 \times 10^{47}$ & -9.679 & 29.66 & $800-2500$ & $0.1-100$ \\
\hline $\mathrm{A}_{2}-2+\mathrm{C}_{4} \mathrm{H}_{4} \rightarrow \mathrm{CS} 5 \overline{7}$ & CS57 & $4.54 \times 10^{266}$ & -75.78 & 133.42 & $800-1600$ & $0.1-100$ \\
\hline${ }^{*} \mathrm{~A}_{2}-2+\mathrm{C}_{4} \mathrm{H}_{4} \rightarrow \mathrm{CS} 60 \mathrm{P}+\mathrm{H}$ & CS57+CS66 & $2.81 \times 10^{37}$ & -6.712 & 31.14 & $800-2500$ & $0.1-100$ \\
\hline $\mathrm{A}_{2}-2+\mathrm{C}_{4} \mathrm{H}_{4} \rightarrow \mathrm{CS} 63-\mathrm{P}+\mathrm{H}$ & CS57 & $1.14 \times 10^{23}$ & -3.522 & 30.26 & $800-2500$ & $0.1-100$ \\
\hline $\mathrm{A}_{2}-2+\mathrm{C}_{4} \mathrm{H}_{4} \rightarrow \mathrm{CS} 7 \stackrel{-}{\mathrm{P}}+\mathrm{H}$ & CS57 & $1.99 \times 10^{44}$ & -9.462 & 30.86 & $800-2500$ & $0.1-100$ \\
\hline $\mathrm{A}_{2}-2+\mathrm{C}_{4} \mathrm{H}_{4} \rightarrow \mathrm{CS} 71 \mathrm{P}+\mathrm{H}$ & CS66+CS72 & $1.17 \times 10^{55}$ & -12.41 & 36.68 & $800-2500$ & $0.1-100$ \\
\hline $\mathrm{A}_{2}-2+\mathrm{C}_{4} \mathrm{H}_{4} \rightarrow \mathrm{CS} 66$ & CS66 & $5.79 \times 10^{172}$ & -47.74 & 86.06 & $800-1800$ & $0.1-100$ \\
\hline $\mathrm{A}_{2}-2+\mathrm{C}_{4} \mathrm{H}_{4} \rightarrow \mathrm{CS} 72$ & CS72 & $1.58 \times 10^{209}$ & -59.4 & 97.92 & $800-1600$ & $0.1-100$ \\
\hline $\mathrm{CS} 60 \_\mathrm{P}+\mathrm{H} \rightarrow \mathrm{CS} 58$ & CS58 & $6.91 \times 10^{258}$ & -74.6 & 110.96 & $800-1300$ & $0.1-100$ \\
\hline${ }^{*} \mathrm{CS} 60 \_\overline{\mathrm{P}}+\mathrm{H} \rightarrow \mathrm{CS} 7 \_\mathrm{P}+\mathrm{H}$ & CS58 & $1.19 \times 10^{29}$ & -4.553 & 25.8 & $800-2500$ & $0.1-100$ \\
\hline $\mathrm{CS} 60 \_\overline{\mathrm{P}}+\mathrm{H} \rightarrow \mathrm{CS} 56_{-}^{-} \mathrm{P}+\mathrm{H}$ & CS58 & $3.49 \times 10^{4}$ & 2.685 & 27.18 & $900-2500$ & $0.1-100$ \\
\hline${ }^{*} \mathrm{CS} 60_{-}^{-} \mathrm{P}+\mathrm{H} \rightarrow \mathrm{A}_{2}-2+\mathrm{C}_{4} \mathrm{H}_{4}$ & CS58+CS66 & $1.99 \times 10^{44}$ & -8.269 & 36.46 & $800-2500$ & $0.1-100$ \\
\hline $\mathrm{CS} \overline{6} 0 \_\mathrm{P}+\mathrm{H} \rightarrow \mathrm{CS} 66$ & CS66 & $3.91 \times 10^{169}$ & -46.38 & 83.62 & $800-2100$ & $0.1-100$ \\
\hline $\mathrm{CS} 60 \_\mathrm{P}+\mathrm{H} \rightarrow \mathrm{CS} 71 \_\mathrm{P}+\mathrm{H}$ & CS66 & $3.40 \times 10^{68}$ & -16.01 & 42.22 & $800-2100$ & $0.1-100$ \\
\hline $\mathrm{A}_{2}-2+\mathrm{C}_{4} \mathrm{H}_{4} \rightarrow \mathrm{CS} 40$ & CS40 & $2.51 \times 10^{277}$ & -77.53 & 155.38 & $800-1800$ & $0.1-100$ \\
\hline $\mathrm{A}_{2}-2+\mathrm{C}_{4} \mathrm{H}_{4} \rightarrow \mathrm{CS} 7 \_\mathrm{P}+\mathrm{H}$ & CS40 & $1.01 \times 10^{48}$ & -9.991 & 46.02 & $800-2500$ & $0.1-100$ \\
\hline $\mathrm{A}_{2}-2+\mathrm{C}_{4} \mathrm{H}_{4} \rightarrow \mathrm{CS} 54-\mathrm{P}+\mathrm{H}$ & $\mathrm{CS} 40+\mathrm{CS} 72$ & $2.30 \times 10^{3}$ & 2.705 & 3.03 & $800-2500$ & $0.1-100$ \\
\hline $\mathrm{A}_{2}-2+\mathrm{C}_{4} \mathrm{H}_{4} \rightarrow \mathrm{CS} 55_{-}^{-} \mathrm{P}+\mathrm{H}$ & CS40 & $5.07 \times 10^{43}$ & -8.305 & 45.60 & $800-2500$ & $0.1-100$ \\
\hline $\mathrm{A}_{2}-2+\mathrm{C}_{4} \mathrm{H}_{4} \rightarrow \mathrm{CS} 56-\mathrm{P}+\mathrm{H}$ & CS40 & $1.27 \times 10^{10}$ & 0.9241 & 35.36 & $900-2500$ & $0.1-100$ \\
\hline $\mathrm{CS} 54 \_\mathrm{P}+\mathrm{H} \rightarrow \mathrm{CS} 40$ & CS40 & $1.75 \times 10^{286}$ & -79.52 & 161.1 & $800-1800$ & $0.1-100$ \\
\hline $\mathrm{CS} 54 \_\overline{\mathrm{P}}+\mathrm{H} \rightarrow \mathrm{CS} 7 \_\mathrm{P}+\mathrm{H}$ & CS40 & $5.71 \times 10^{61}$ & -13.42 & 55.80 & $800-2500$ & $0.1-100$ \\
\hline $\mathrm{CS} 54 \_\overline{\mathrm{P}}+\mathrm{H} \rightarrow \mathrm{CS} 55_{-} \mathrm{P}+\mathrm{H}$ & CS40 & $4.26 \times 10^{58}$ & -12.04 & 56.66 & $800-2500$ & $0.1-100$ \\
\hline $\mathrm{CS} 54 \_\mathrm{P}+\mathrm{H} \rightarrow \mathrm{CS} 56{ }^{-} \mathrm{P}+\mathrm{H}$ & CS40 & $2.33 \times 10^{17}$ & -0.7257 & 40.14 & $1200-2500$ & $0.1-100$ \\
\hline $\mathrm{CS} 54-\mathrm{P}+\mathrm{H} \rightarrow \mathrm{A}_{2}-2+\mathrm{C}_{4} \mathrm{H}_{4}$ & $\mathrm{CS} 40+\mathrm{CS} 72$ & $8.52 \times 10^{61}$ & -12.93 & 57.40 & $800-2500$ & $0.1-100$ \\
\hline $\mathrm{CS} 5 \overline{5} 4 \mathrm{P}+\mathrm{H} \rightarrow \mathrm{CS} 72$ & CS72 & $5.86 \times 10^{206}$ & -57.93 & 98.6 & $800-1700$ & $0.1-100$ \\
\hline $\mathrm{CS} 54 \_\mathrm{P}+\mathrm{H} \rightarrow \mathrm{CS} 71 \_\mathrm{P}+\mathrm{H}$ & CS72 & $6.47 \times 10^{9}$ & 0.4187 & 4.44 & $800-2500$ & $0.1-100$ \\
\hline $\mathrm{CS} 55 \mathrm{P}+\mathrm{H} \rightarrow \mathrm{CS} 40$ & CS40 & $9.84 \times 10^{276}$ & -77.12 & 152.78 & $800-1700$ & $0.1-100$ \\
\hline $\mathrm{CS} 55 \_\mathrm{P}+\mathrm{H} \rightarrow \mathrm{CS} 7 \_\mathrm{P}+\mathrm{H}$ & CS40 & $1.18 \times 10^{53}$ & -11.15 & 46.74 & $800-2500$ & $0.1-100$ \\
\hline $\mathrm{CS} 55 \overline{\mathrm{P}}+\mathrm{H} \rightarrow \mathrm{CS} 5 \overline{4} \mathrm{P}+\mathrm{H}$ & CS40 & $5.23 \times 10^{56}$ & -11.74 & 47.58 & $800-2500$ & $0.1-100$ \\
\hline
\end{tabular}




\begin{tabular}{|c|c|c|c|c|c|c|}
\hline $\mathrm{CS} 55 \_\mathrm{P}+\mathrm{H} \rightarrow \mathrm{CS} 56 \_\mathrm{P}+\mathrm{H}$ & CS40 & $1.24 \times 10^{21}$ & -1.83 & 41.70 & $800-2500$ & $0.1-100$ \\
\hline $\mathrm{CS} 55_{-}^{-} \mathrm{P}+\mathrm{H} \rightarrow \mathrm{A}_{2}-2+\mathrm{C}_{4} \mathrm{H}_{4}$ & CS40 & $7.87 \times 10^{53}$ & -10.83 & 48.66 & $800-2500$ & $0.1-100$ \\
\hline CS56_P+H $\rightarrow$ CS7_P+H & CS46 & $7.31 \times 10^{16}$ & -0.8238 & 9.46 & $800-2500$ & $0.1-100$ \\
\hline $\mathrm{CS} 56 \_\mathrm{P}+\mathrm{H} \rightarrow \mathrm{CS} 54 \_\mathrm{P}+\mathrm{H}$ & CS46 & $1.35 \times 10^{19}$ & -1.29 & 40.06 & $1000-2500$ & $0.1-100$ \\
\hline $\mathrm{CS} 56 \_\mathrm{P}+\mathrm{H} \rightarrow \mathrm{CS} 55 \_\mathrm{P}+\mathrm{H}$ & CS46 & $3.57 \times 10^{26}$ & -3.202 & 51.86 & $1200-2500$ & $0.1-100$ \\
\hline $\mathrm{CS} 56 \_\mathrm{P}+\mathrm{H} \rightarrow \mathrm{A}_{2}-2+\mathrm{C}_{4} \mathrm{H}_{4}$ & CS46 & $1.05 \times 10^{20}$ & -1.409 & 43.86 & $1100-2500$ & $0.1-100$ \\
\hline $\mathrm{A}_{2}-1+\mathrm{C}_{4} \mathrm{H}_{4} \rightarrow$ all products & $\mathrm{CS} 2$ & $8.10 \times 10^{1}$ & 3.206 & 1.641 & $800-2500$ & $\mathrm{H}-\mathrm{P}^{\mathrm{a}}$ \\
\hline $\mathrm{A}_{2}-1+\mathrm{C}_{4} \mathrm{H}_{4} \rightarrow$ all products & CS20 & $4.73 \times 10^{2}$ & 2.831 & 1.452 & $800-2500$ & $\mathrm{H}-\mathrm{P}^{\mathrm{a}}$ \\
\hline $\mathrm{A}_{2}-2+\mathrm{C}_{4} \mathrm{H}_{4} \rightarrow$ all products & CS40+CS72 & $1.23 \times 10^{2}$ & 3.053 & 1.834 & $800-2500$ & $\mathrm{H}-\mathrm{P}^{\mathrm{a}}$ \\
\hline $\mathrm{A}_{2}-2+\mathrm{C}_{4} \mathrm{H}_{4} \rightarrow$ all products & CS57+CS66 & $4.26 \times 10^{2}$ & 2.928 & 0.752 & $800-2500$ & $\mathrm{H}-\mathrm{P}^{\mathrm{a}}$ \\
\hline $\mathrm{A}_{2}-1+\mathrm{C}_{4} \mathrm{H}_{4} \rightarrow \mathrm{A}_{2}+\mathrm{i}-\mathrm{C}_{4} \mathrm{H}_{3}$ & - & $2.91 \times 10^{0}$ & 3.579 & 5.30 & $800-2500$ & $\mathrm{H}-\mathrm{P}^{\mathrm{a}}$ \\
\hline $\mathrm{A}_{2}+\mathrm{i}-\mathrm{C}_{4} \mathrm{H}_{3} \rightarrow \mathrm{A}_{2}-1+\mathrm{C}_{4} \mathrm{H}_{4}$ & - & $4.25 \times 10^{0}$ & 3.468 & 21.16 & $800-2500$ & $\mathrm{H}-\mathrm{P}^{\mathrm{a}}$ \\
\hline $\mathrm{A}_{2}-1+\mathrm{C}_{4} \mathrm{H}_{4} \rightarrow \mathrm{A}_{2}+\mathrm{n}-\mathrm{C}_{4} \mathrm{H}_{3}$ & - & $9.00 \times 10^{-1}$ & 3.77 & 8.49 & $800-2500$ & $\mathrm{H}-\mathrm{P}^{\mathrm{a}}$ \\
\hline $\mathrm{A}_{2}+\mathrm{n}-\mathrm{C}_{4} \mathrm{H}_{3} \rightarrow \mathrm{A}_{2}-1+\mathrm{C}_{4} \mathrm{H}_{4}$ & - & $3.71 \times 10^{1}$ & 3.468 & 9.58 & $800-2500$ & $\mathrm{H}-\mathrm{P}^{\mathrm{a}}$ \\
\hline $\mathrm{A}_{2}-2+\mathrm{C}_{4} \mathrm{H}_{4} \rightarrow \mathrm{A}_{2}+\mathrm{i}-\mathrm{C}_{4} \mathrm{H}_{3}$ & - & $4.97 \times 10^{0}$ & 3.525 & 5.24 & $800-2500$ & $\mathrm{H}-\mathrm{P}^{\mathrm{a}}$ \\
\hline $\mathrm{A}_{2}+\mathrm{i}-\mathrm{C}_{4} \mathrm{H}_{3} \rightarrow \mathrm{A}_{2}-2+\mathrm{C}_{4} \mathrm{H}_{4}$ & - & $3.34 \times 10^{0}$ & 3.512 & 20.92 & $800-2500$ & $\mathrm{H}-\mathrm{P}^{\mathrm{a}}$ \\
\hline $\mathrm{A}_{2}-2+\mathrm{C}_{4} \mathrm{H}_{4} \rightarrow \mathrm{A}_{2}+\mathrm{n}-\mathrm{C}_{4} \mathrm{H}_{3}$ & - & $2.73 \times 10^{0}$ & 3.615 & 8.78 & $800-2500$ & $\mathrm{H}-\mathrm{P}^{\mathrm{a}}$ \\
\hline $\mathrm{A}_{2}+\mathrm{n}-\mathrm{C}_{4} \mathrm{H}_{3} \rightarrow \mathrm{A}_{2}-2+\mathrm{C}_{4} \mathrm{H}_{4}$ & - & $1.23 \times 10^{1}$ & 3.576 & 9.04 & $800-2500$ & $\mathrm{H}-\mathrm{P}^{\mathrm{a}}$ \\
\hline
\end{tabular}

*Reactions filtered by pathway analysis.

${ }^{a}$ High-pressure limit 